\title{
Dynamic Downscaling of the Impact of Climate Change on the Ocean Circulation in the Galápagos Archipelago
}

\author{
Yanyun Liu, ${ }^{1,2,3}$ Lian Xie, ${ }^{1}$ John M. Morrison, ${ }^{4}$ and Daniel Kamykowski ${ }^{1}$ \\ ${ }^{1}$ Department of Marine, Earth and Atmospheric Sciences, North Carolina State University, Raleigh, NC 27695-8208, USA \\ ${ }^{2}$ Cooperative Institute for Marine and Atmospheric Studies, University of Miami, Miami, FL 33129-1098, USA \\ ${ }^{3}$ Atlantic Oceanographic and Meteorological Laboratory, NOAA, Miami, FL 33129-1026, USA \\ ${ }^{4}$ Department of Physics and Physical Oceanography, University of North Carolina at Wilmington, Wilmington, NC 28403-5606, USA
}

Correspondence should be addressed to Lian Xie; xie@ncsu.edu

Received 28 February 2013; Revised 8 May 2013; Accepted 2 June 2013

Academic Editor: Bin Liu

Copyright (C) 2013 Yanyun Liu et al. This is an open access article distributed under the Creative Commons Attribution License, which permits unrestricted use, distribution, and reproduction in any medium, provided the original work is properly cited.

\begin{abstract}
The regional impact of global climate change on the ocean circulation around the Galápagos Archipelago is studied using the Hybrid Coordinate Ocean Model (HYCOM) configured for a four-level nested domain system. The modeling system is validated and calibrated using daily atmospheric forcing derived from the NCEP/NCAR reanalysis dataset from 1951 to 2007 . The potential impact of future anthropogenic global warming (AGW) in the Galápagos region is examined using the calibrated HYCOM with forcing derived from the IPCC-AR4 climate model. Results show that although the oceanic variability in the entire Galápagos region is significantly affected by global climate change, the degree of such effects is inhomogeneous across the region. The upwelling region to the west of the Isabella Island shows relatively slower warming trends compared to the eastern Galápagos region. Diagnostic analysis suggests that the variability in the western Galápagos upwelling region is affected mainly by equatorial undercurrent (EUC) and Panama currents, while the central/east Galápagos is predominantly affected by both Peru and EUC currents. The inhomogeneous responses in different regions of the Galápagos Archipelago to future AGW can be explained by the incoherent changes of the various current systems in the Galápagos region as a result of global climate change.
\end{abstract}

\section{Introduction}

The Galápagos Islands (Figure 1) are an oceanic archipelago located near the equator in the eastern tropical Pacific. It reasonably claims to possess the most distinctive marine flora and fauna, as well as unique species for any area of its size worldwide [1]. The principal reason why the Galápagos Islands feature such great diversity lies in its positioning in a complex transition zone between tropical, subtropical, and upwelling zones. The Galápagos archipelago ecosystem is mainly affected by three different surface and subsurface currents. The major currents affecting the Galápagos are the westward South Equatorial Current (SEC) and the eastward Equatorial Undercurrent (EUC) [2-5].

The EUC is thought to be the major oceanographic feature affecting the production in the Galápagos Marine Reserve (GMR) and is important defining physical process to influence the very high local production at certain sites
[6]. Around the GMR, the nutrient flux to the euphotic zone from cold bathymetrically deflected upwelled water from the eastward flowing EUC is the main nutrient source in the Galápagos archipelago. The upwelling events impacting upon the west of the archipelago vary in strength, size, and stability under the influence of localized current systems and forcing effects. The EUC flow pathways and upwelling are linked directly to the submarine topography, which introduces obstacles to the eastward path of the undercurrent. This deflects water to the north in the northern hemisphere and to the south in the southern hemisphere. The EUC waters are cooler, saltier, and higher in nutrients and iron than waters found over the eastern portion of the Archipelago and directly result in the large phytoplankton bloom observed in the Sea-viewing Wide Field-of-view sensor (SeaWiFs) and Advanced Very High Resolution Radiometer (AVHRR). The result indicates that when there is not a EUC present (for example, during intense El Niño events), the intense 


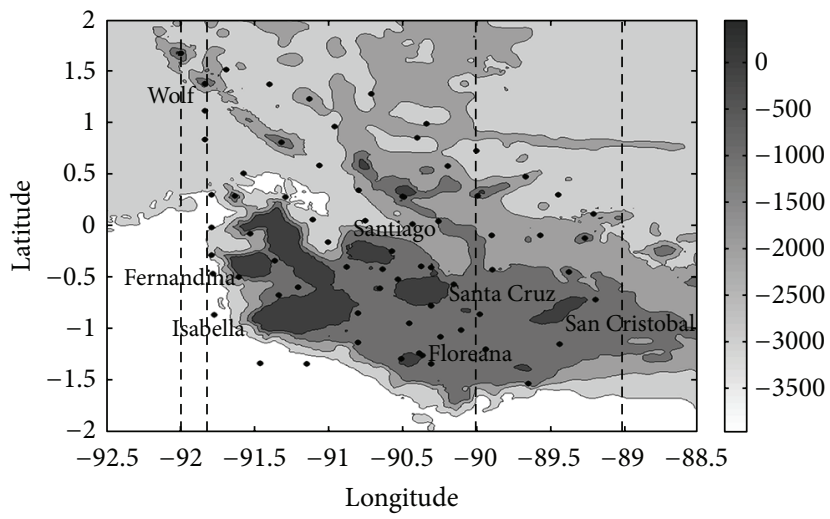

Figure 1: Bathymetry map and sampling stations (for 2005-2006 cruises) of the Galápagos Archipelago. The lines show the vertical sections used in Figures 15 and 17 (along the $92^{\circ} \mathrm{W}, 91.8^{\circ} \mathrm{W}, 90^{\circ} \mathrm{W}$, and $89^{\circ} \mathrm{W}$ ).

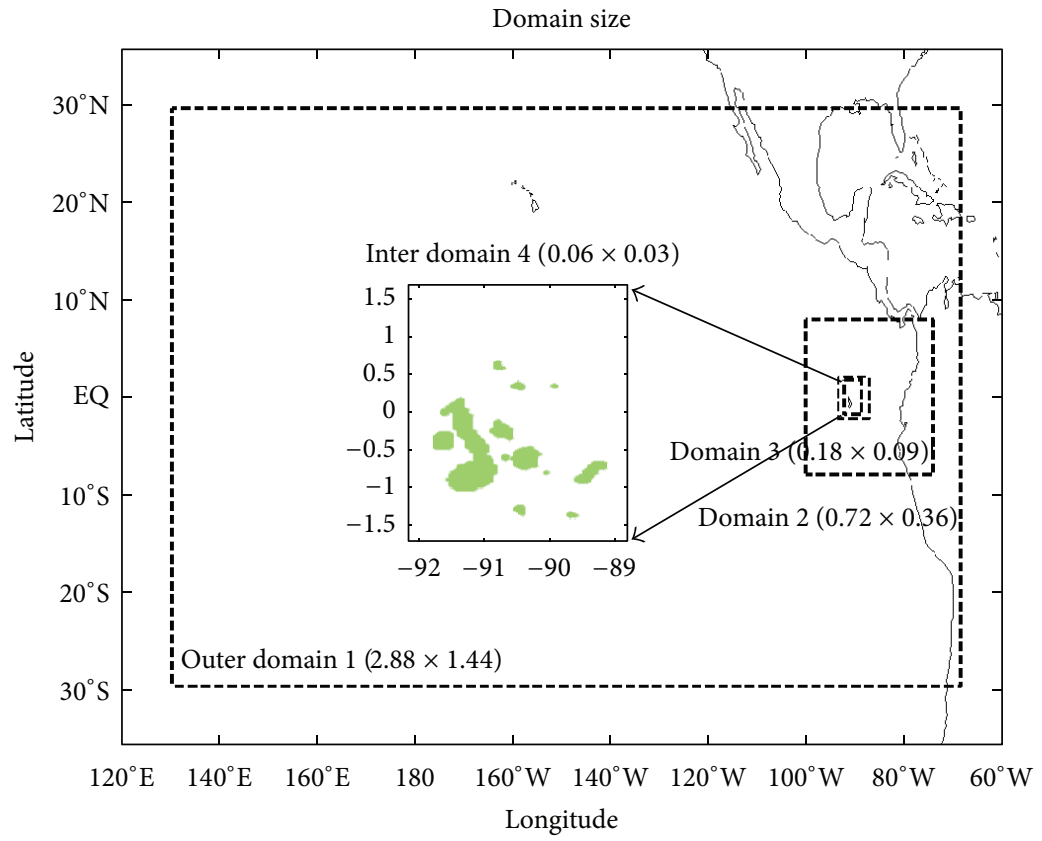

FIgURE 2: Model domain size of the outer domain (with the resolution $2.88^{\circ} \times 1.44^{\circ}$ ), the intermediate domains (covering the Eastern Pacific Ocean, with the resolutions of $0.72^{\circ} \times 0.36^{\circ}$ and $0.18^{\circ} \times 0.09^{\circ}$ ), and the inter domain with the highest resolution of $0.06^{\circ} \times 0.03^{\circ}$.

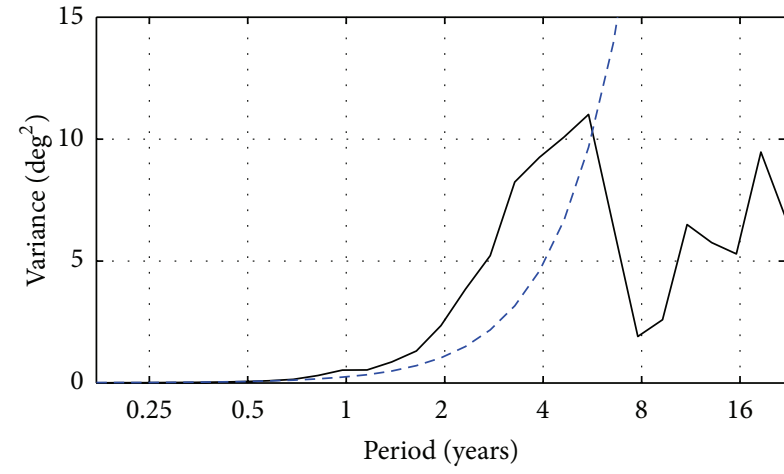

(a) Spectrum of SSTA in Nino3.4 region (Model)

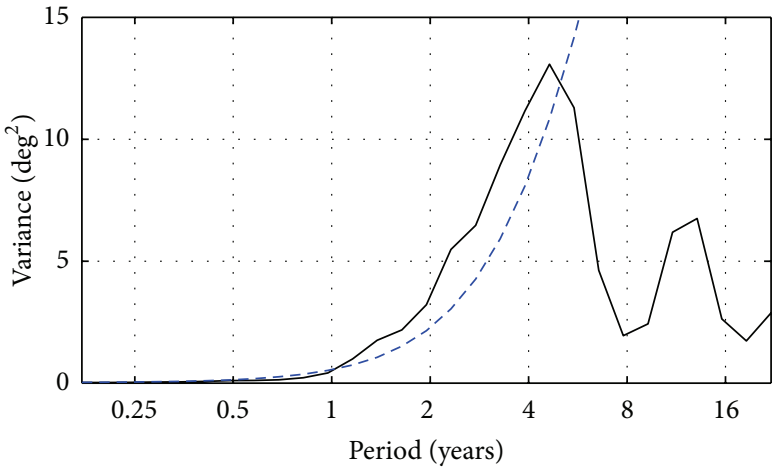

(b) Spectrum of SSTA in Nino3.4 region (Obs)

FIGURE 3: The power spectrum of the SST anomalies in the Nino3 region during 1950-2006 obtained from the (a) model simulation and (b) observation. 


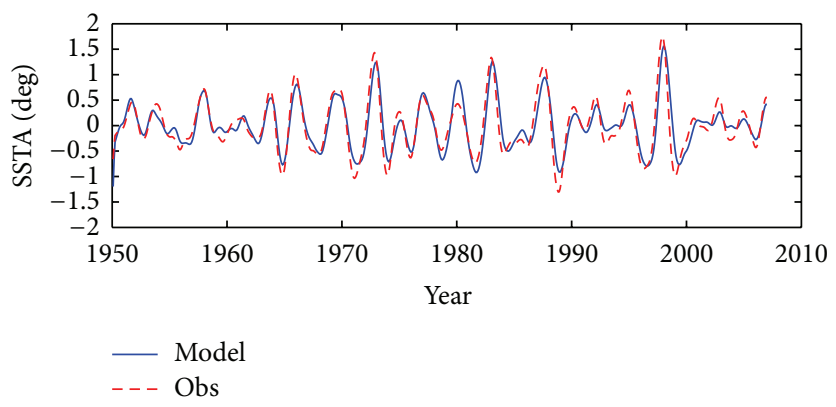

FIgURE 4: The bandpass filtered observed (dashed) and HYCOM-simulated SST anomalies (solid) in Nino3.4 region from 1950 to 2006.

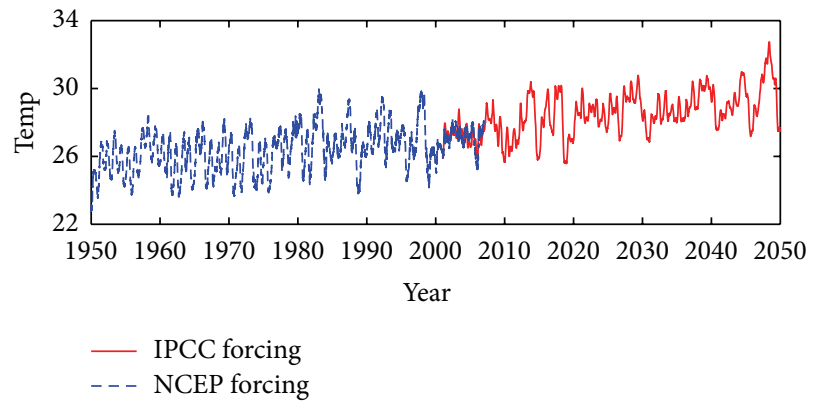

FIgURE 5: The simulated SST in Nino3.4 region from 1950 to 2006 (Blue) forced by NCEP atmospheric forcing and simulated SST from 2001 to 2050 (red) forced by IPCC-AR4 SERS A1B atmospheric forcing using HYCOM model.

biological activity normally sustaining the GMR will be absent. The 1982-83 and 1997-98 El Niño events, in particular, were the most extreme for the 20th century and had a devastating effect on marine life in the Galápagos region. During the El Niño event, the EUC weakens, the surface water warms, macronutrients are reduced, the primary production decreases, and fish numbers diminish [7, 8]. El Niño events now occur more frequently than they did 7000-15,000 years ago $[9,10]$. Such an increase in the frequency and severity of El Niño events is a concern for the conservation of endangered species $[11,12]$. On the other hand, Collins et al. [13] suggest that future changes in ENSO frequency with increased greenhouse gas forcing are still unclear despite considerable progress in our understanding of the impact of climate change on many of the processes that contribute to El Niño variability. There are too few model studies to predict how the ocean circulation around the GMR is likely to change during the 21st century. Thus, here we will explore more about whether El Niño events will continue to increase in frequency and intensity in a warmer future climate and what regional changes might occur in the Galápagos region in the next 50100 years.

There are two seemingly conflicting views about whether SST warming has already occurred in the Galápagos region. Conroy et al. [14] suggest that SST warming already occurred in the Galápagos region, and the SST in eastern tropical Pacific Ocean in general rose about 0.8 degrees in the past 40 years. However, a study by Dunbar et al. [15] suggests the contrary and found no warming occurred in the Galápagos region. As shown by Dunbar et al. [15], the coral record from Urvina Bay shows no warming trend. Besides, a more recent research [16] suggests that there are different temperature trends in the eastern tropical Pacific in different gridded SST products. Deser et al. [16] examined different gridded SST dataset and found that there are discrepancies about the different temperature trends in the eastern Pacific. Their results show that two of the SST reconstructions (including HadISST [17] and Kaplan Extended SST [18]) exhibit statistically significant cooling trends over the eastern equatorial Pacific, in disagreement with the un-interpolated SST and marine air temperature datasets which show statistically significant warming in this region. Previous studies show that there are discrepancies about the different temperature trends in the eastern Pacific and the Galápagos region. The issue is then, which opinion is correct? Is or is not there a warming trend around the GMR? Why do different studies indicate opposite conclusions? In this paper, we attempt to address the previous controversy and reconcile the differences found in previous studies using a three-dimensional ocean general circulation model (HYCOM) driven by both present-day climate (19502007) and future anthropogenic forcing derived from the Fourth Assessment Report (AR4) of the Intergovernmental Panel on Climate Change (IPCC) [19] Special Report: Emissions Scenarios (SRES) A1B scenario. As suggested by Karnauskas et al. [20], the EUC in the eastern Pacific Ocean can be underestimated due to insufficient ocean resolution. Therefore, here we use a downscaled high-resolution model to assess the potential impact of future anthropogenic global warming $(\mathrm{AGW})$ on the GMR. The rest of the paper is organized as follows: in Section 2, we describe the HYCOM model configuration and the experiments conducted. In Section 3, the simulated tropical ocean circulation around the 


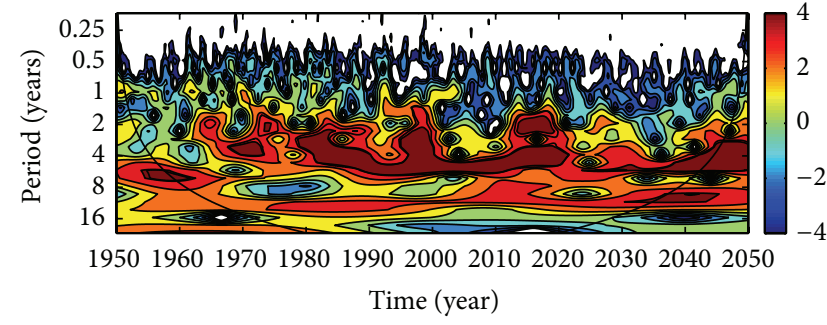

(a) Nino3.4 SSTA wavelet power spectrum (1950-2050)

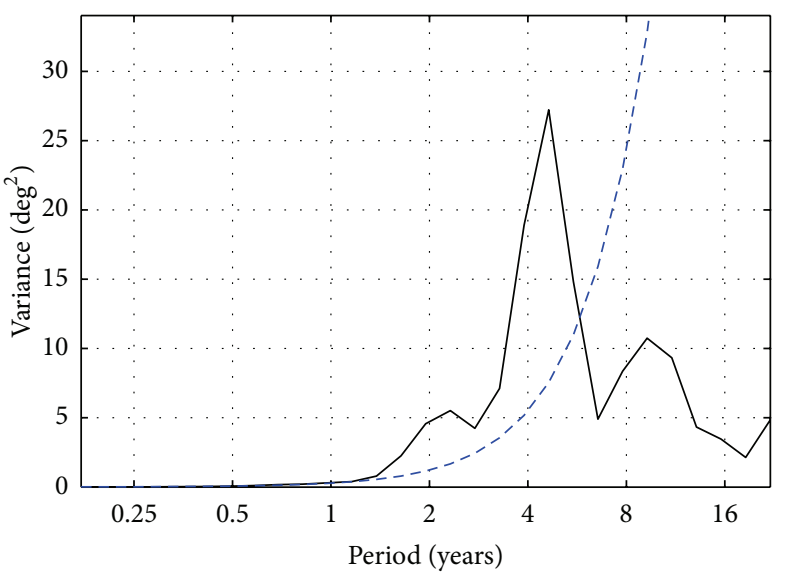

(b) Spectrum of SSTA in Nino3.4 region

Figure 6: The evolution of the difference of the sea level pressure anomaly $(\triangle \mathrm{SLP})$ between East Pacific $\left(80^{\circ} \mathrm{E}-160^{\circ} \mathrm{E}, 5^{\circ} \mathrm{S}-5^{\circ} \mathrm{N}\right)$ and $\mathrm{West}$ Pacific $\left(160^{\circ} \mathrm{W}-80^{\circ} \mathrm{W}, 5^{\circ} \mathrm{S}-5^{\circ} \mathrm{N}\right)$ and zonal wind stress anomaly in equatorial Pacific $\left(120^{\circ} \mathrm{E}-70^{\circ} \mathrm{W}, 5^{\circ} \mathrm{S}-5^{\circ} \mathrm{N}\right)$ since the 20 th century from IPCCAR4IPCC-AR4 data.

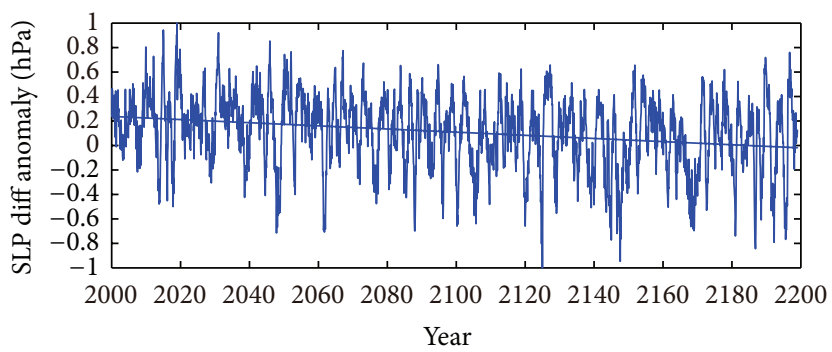

(a) Difference of SLP anomaly

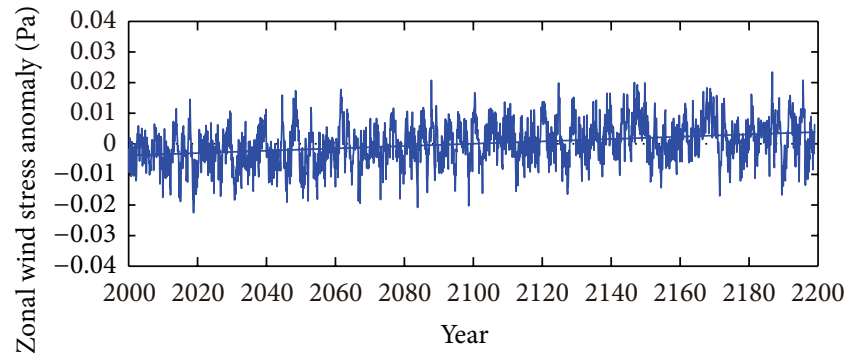

(b) Zonal wind stress anomaly

Figure 7: The evolution of the difference of the sea level pressure anomaly $(\triangle \mathrm{SLP})$ between East Pacific $\left(80^{\circ} \mathrm{E}-160^{\circ} \mathrm{E}, 5^{\circ} \mathrm{S}-5^{\circ} \mathrm{N}\right)$ and West Pacific $\left(160^{\circ} \mathrm{W}-80^{\circ} \mathrm{W}, 5^{\circ} \mathrm{S}-5^{\circ} \mathrm{N}\right)$ and zonal wind stress anomaly in equatorial Pacific $\left(120^{\circ} \mathrm{E}-70^{\circ} \mathrm{W}, 5^{\circ} \mathrm{S}-5^{\circ} \mathrm{N}\right)$ since the 20 th century from IPCC-AR4 data.

GMR using the NCEP and IPCC-AR4 A1B scenario forcing is presented and compared. The different physical variables are specifically compared and analyzed around the GMR during the different El Niño and La Niña cases in this section. How the different regions are influenced by different current system will be discussed in Section 4. Results are summarized in Section 5.

\section{Model Description and Experiment Design}

2.1. Model Introduction and Dataset Description. HYCOM is a primitive equation ocean general circulation model using density, pressure, and sigma coordinates in the vertical. It has evolved from the Miami Isopycnic Coordinate Ocean Model (MICOM) and is isopyinc in the open stratified ocean but reverts to a terrain-following coordinate in shallow coastal regions and to $z$-level coordinates near the surface in the mixed layer. This generalized vertical coordinate approach is dynamic in space and time via the layered continuity equation and permits the existence of zero thickness layers [21-23].

The HYCOM simulations were carried out using a nesting scheme of four ever-increasing resolution domains
(Figure 2). The largest domain covers the Pacific Ocean with a grid size of $2.88^{\circ} \times 1.44^{\circ}$ in zonal and meridional directions, respectively. The second and third domains embedded within the Pacific domain use a grid size of $0.72^{\circ} \times 0.36^{\circ}$ and $0.18^{\circ} \times 0.09^{\circ}$ covering the Eastern Pacific Ocean. Finally, the highest resolution domain has a grid size of $0.06^{\circ} \times 0.03^{\circ}$ (about $6.67 \mathrm{~km} \times 3.32 \mathrm{~km}$ ) that is centered on the GMR $\left(92.16^{\circ} \mathrm{W}-88.74^{\circ} \mathrm{W}, 1.71^{\circ} \mathrm{S}-1.71^{\circ} \mathrm{N}\right)$. All domains have a vertical resolution of 26 layers that stretch or shrink vertically as a function of total depth according to the hybrid coordinate frame discussed previous. The nested-grid HYCOM was driven by daily surface wind stress, surface air temperature, atmospheric specific humidity, net shortwave radiation, net long-wave radiation, and precipitation fields. The simulations with these four different resolutions have been performed under identical daily meteorological forcing fields derived from the NCEP/NCAR reanalysis data from 1950-2007. The latent and sensible heat fluxes were calculated during model runs using the model sea surface temperature and the bulk formulation $[24,25]$. Boundary conditions were provided by buffer zones that are ten grid points wide within which temperature, salinity, and interface depth are relaxed to Levitus climatological values $[26,27]$, which have 


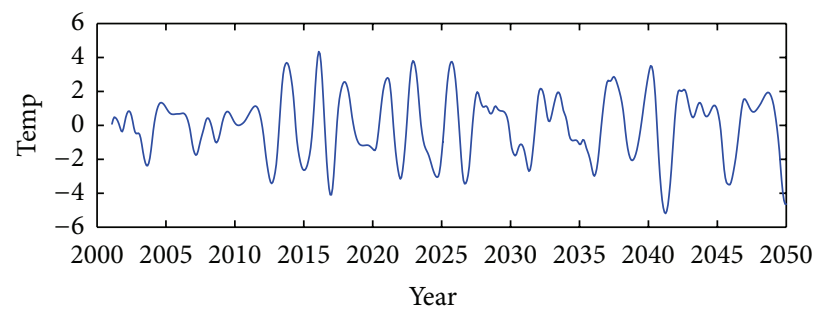

FIgURE 8: The bandpass filtered HYCOM-simulated SST in Nino3.4 region from 2001-2050.

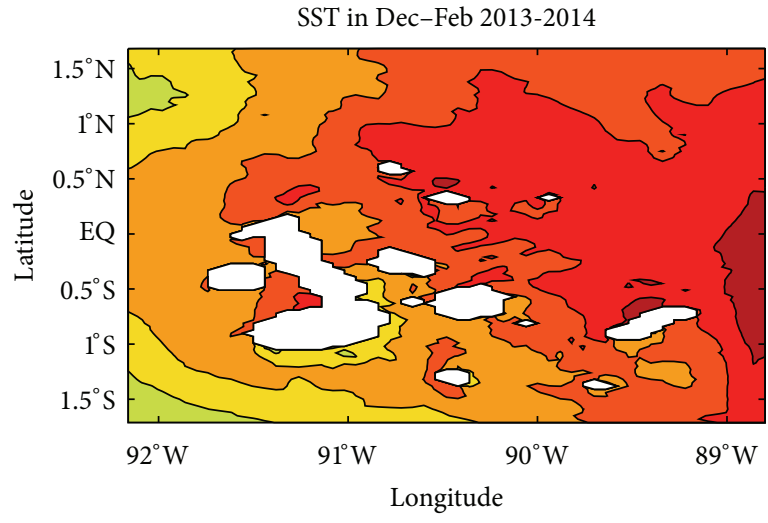

(a)

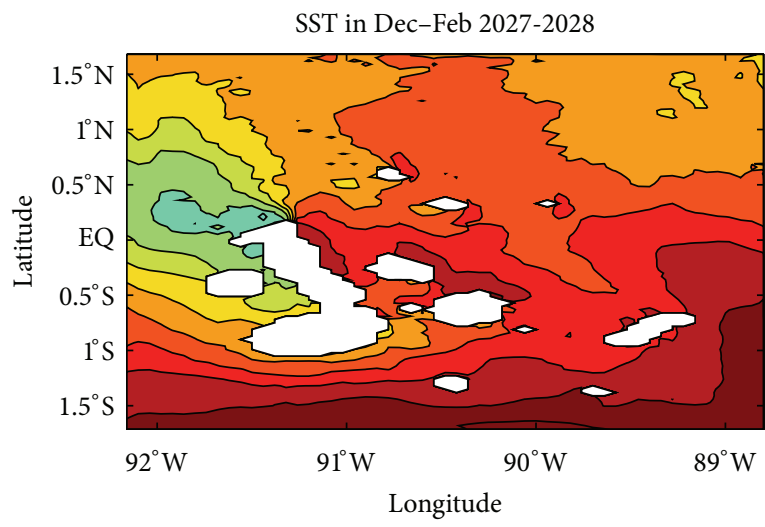

(c)

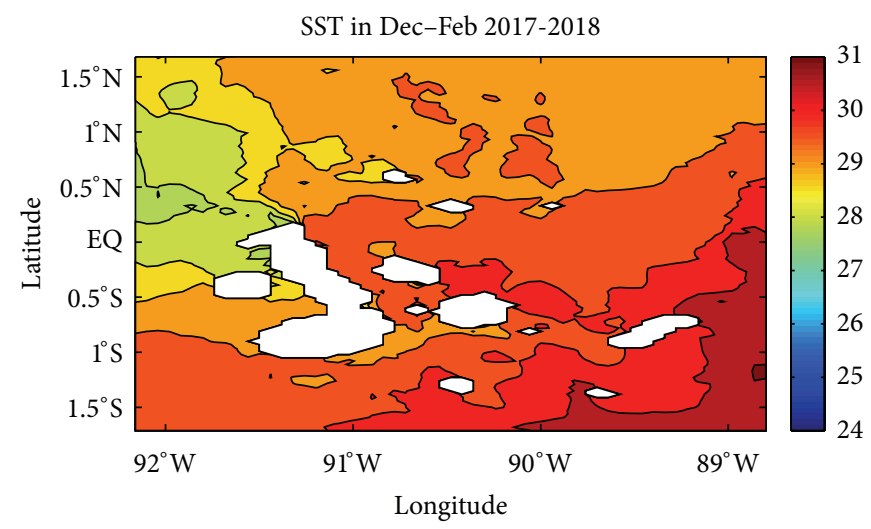

(b)

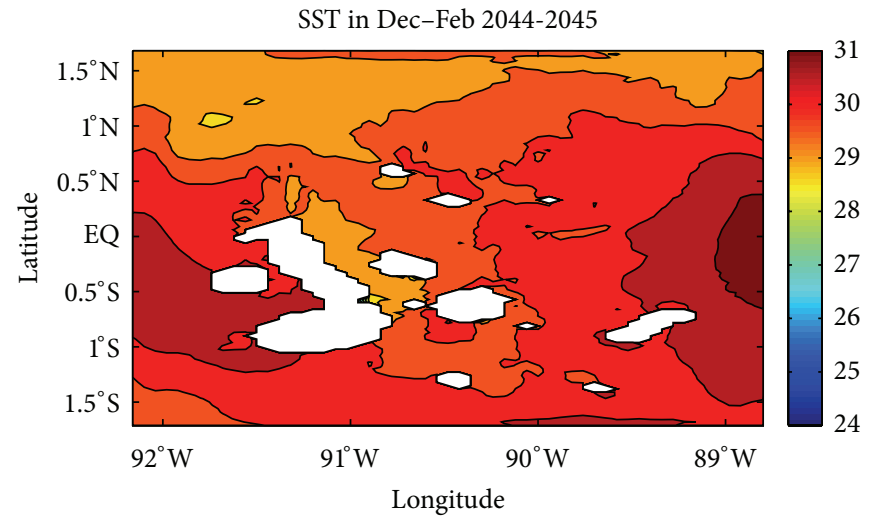

(d)

FIgURE 9: The SST around the GMR during the El Niño cases: (a) in Dec-Feb in 2013-2014, (b) in Dec-Feb in 2017-2018, (c) in Dec-Feb in 2027-2028, and (d) in Dec-Feb in 2044-2045.

been vertically remapped to hybrid vertical coordinates. The KPP vertical mixing model of Large et al. [28] was also used. For the experiments with the grid size of $2.88^{\circ}$, $0.72^{\circ}$, and $0.18^{\circ}$ on zonal direction, the bathymetry was derived from the ETOPO2 data (National Geophysical Data Center), which contains digital data bases of seafloor and land elevations on a 2-minute latitude/longitude grid and is interpolated on the model grids of different resolutions. In the simulation with the resolution of $0.06^{\circ}$ (near the Galápagos Islands), the bathymetry was derived from the $0.01^{\circ}$ data processed by William Chadwick, Oregon State University (http://www.pmel.noaa.gov/vents/staff/chadwick/ Galápagos.html). The model was spun up for fifty years using the NCEP forcing and then ran for fifty years from 2001 to
2050 under the derived forcing from the IPCC-AR4 climate model. We will discuss the results in the next section.

Comparisons among the results from the simulations in each of the two resolution domains indicate that the fine resolution simulations are more accurate and have a more realistic spectrum of oceanographic variability. For example, the simulation with the resolution of $0.06^{\circ} \times 0.03^{\circ}$ can depict the intraseasonal signal from the tropical instability waves (TIW), as well as the annual and the interannual signals, whereas the low-resolution global model failed to depict TIW signal [29]. The ocean is also sensitive to the frequency of the atmospheric forcing. In a controlled experiment where the atmospheric forcing frequency was reduced from daily frequency to monthly, the results simulated by the ocean 


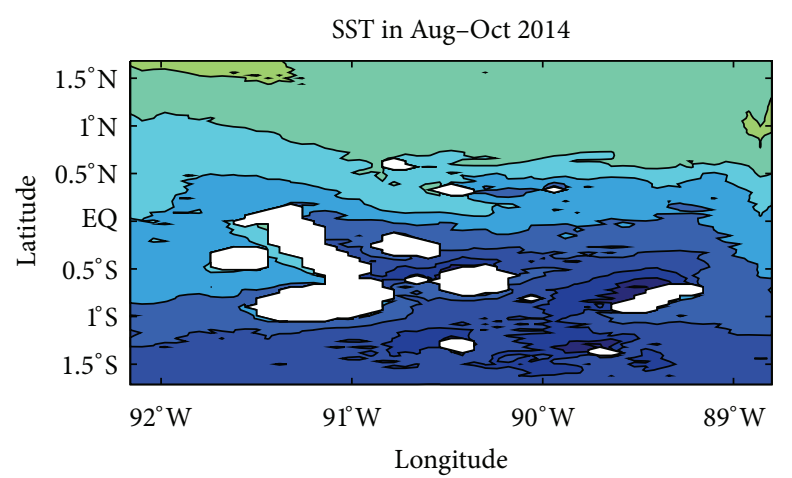

(a)

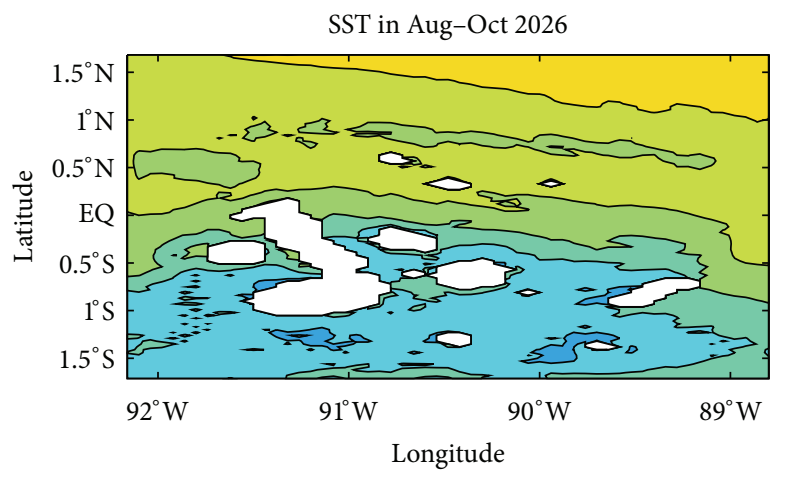

(c)

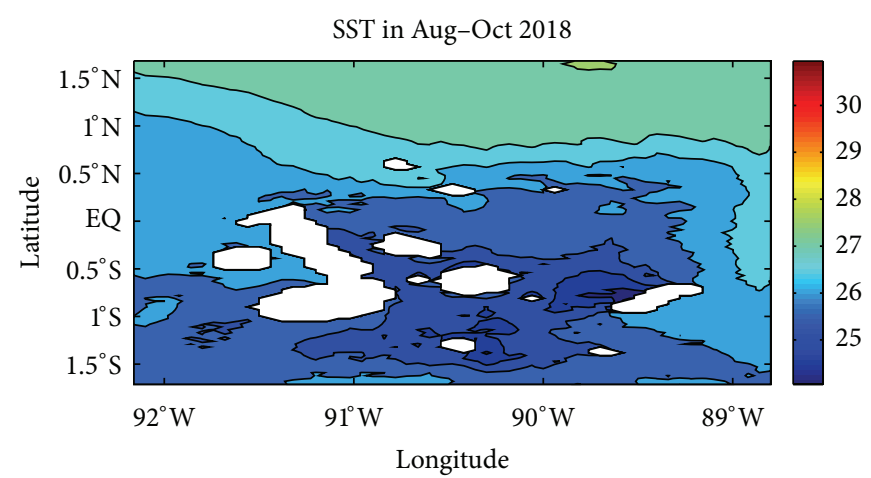

(b)

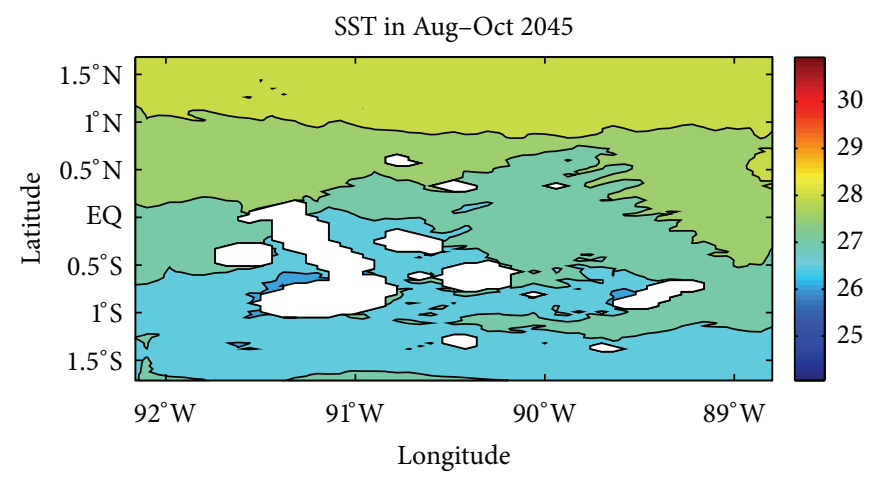

(d)

FIgure 10: The SST around the GMR during the La Niña cases: (a) in Aug-Oct in 2014, (b) in Aug-Oct in 2018, (c) in Aug-Oct in 2026, and (d) in Aug-Oct in 2045.

model are shown to be less accurate than those simulated using daily forcing.

2.2. Experiment Design. The nested HYCOM is first validated and calibrated with daily atmospheric forcing derived from the NCEP/NCAR [30] reanalysis dataset for the period of 1950-2007 (Expt 1). The model is then applied to downscale the impact of climate change on the ocean circulation and water mass characteristics in the GMR under global warming scenarios forced by IPCC-AR4 SRES A1B Emissions Scenario from 2001-2050 (Expt 2). Here we use the model data from the Hadley Center (UKMO-HadCM3 model). The highresolution runs are conducted near the Galápagos for all El Niño, and La Niña years from 2001 to 2050 observed in Expt 2 . In all cases, the model was initialized with temperature and salinity from the Levitus monthly climatology [26, 27] and run for 50 years. For the future AGW simulation, the monthly IPCC-AR4 SRES A1B Emissions Scenario from 2001-2050 is used as the atmospheric forcing to perform the simulation (Expt 2).

\section{Results}

3.1. Validation and Calibration Experiments. For the first set of experiments (Expt 1), the impact of historical climate on the ocean variability around GMR in the past fifty years is simulated using the NCEP/NCAR reanalysis data as the climatic forcing. Here, the run employed a grid size of $2.88^{\circ} \times 1.44^{\circ}$ in zonal and meridional directions, respectively. The experiment domain covers the whole Pacific ocean and has a vertical resolution defined by 26 layers that stretch or shrink vertically as a function of total depth according to the hybrid coordinate frame.

The results indicate that with prescribed atmospheric forcing, the nested HYCOM model can reproduce the major characteristics of the ocean circulation and its variability in the Galápagos region, including the ENSO events, annual and seasonal cycles, upwelling system, and local and regional current systems. The area-averaged SST anomalies in the Nino3.4 region $\left(5^{\circ} \mathrm{S}-5^{\circ} \mathrm{N}, 150^{\circ} \mathrm{W}-90^{\circ} \mathrm{W}\right)$ are used to index ENSO variability [31]. In this study, the simulated SST anomalies are computed from the departure of the monthly mean SST from average climatology of the simulated SST from 1950 to 2006. The observational datasets used for comparison came from the $2^{\circ} \times 2^{\circ}$ Reynolds and Smith [32] optimal interpolation (OI) SST (often referred to "Reynolds SST"), from 1950 to 2006. The power spectrum of the SST anomalies (Figure 3) showed that the main ENSO period in the model is approximately 2 to 7 years, similar to the observed period. The peak amplitude of the simulated power spectrum is comparable to that of the Reynolds. In order to evaluate the model's skill in ENSO simulation, we extracted the inter-annual signal from both the simulated and the observed SST anomalies using a band-pass wavelet filter with a window of 2-7 years as indicated by the power spectrum (Figure 3). Figure 4 shows the observed (solid) and HYCOM-simulated (dashed) 2-7 


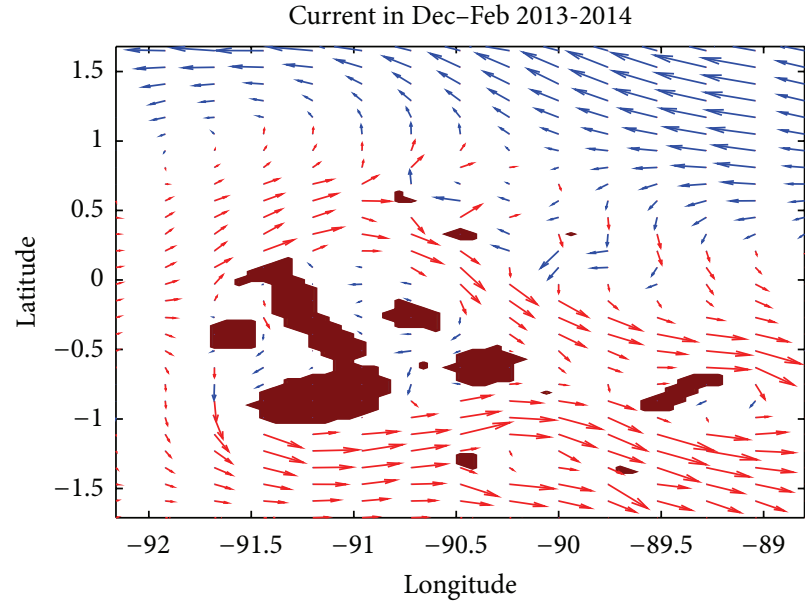

(a)

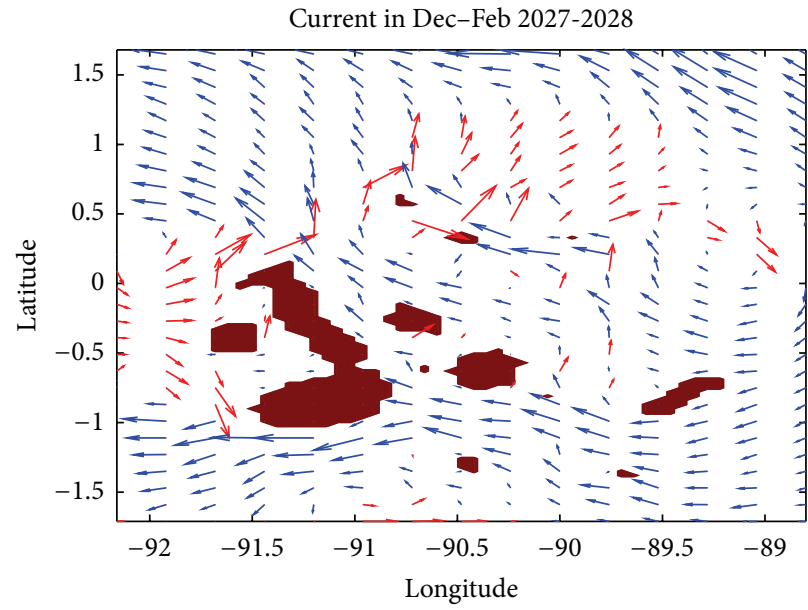

(c)

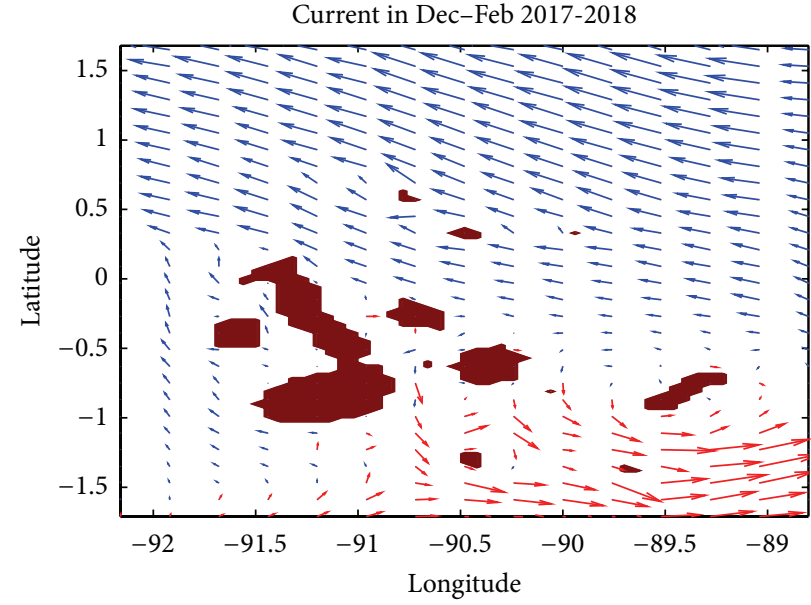

(b)

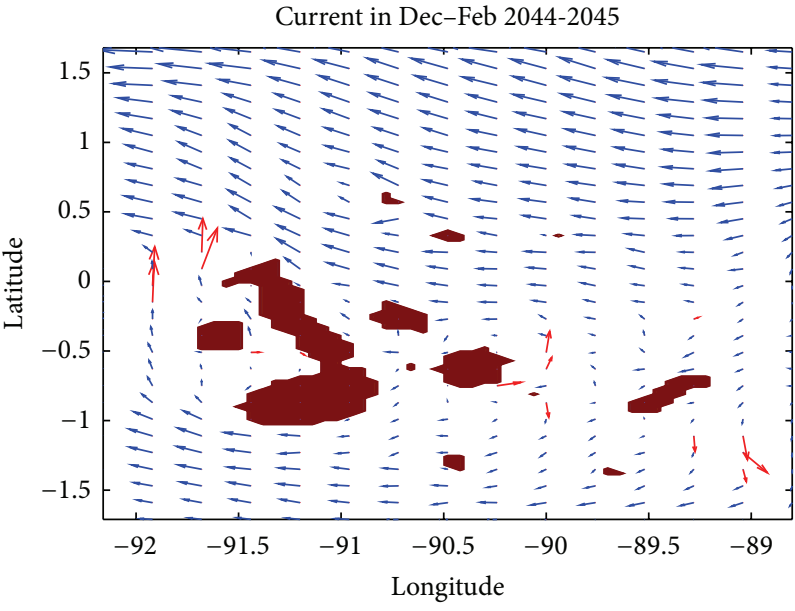

(d)

Figure 11: The surface current around the GMR during the El Niño cases: (a) in Dec-Feb in 2013-2014, (b) in Dec-Feb in 2017-2018, (c) in Dec-Feb in 2027-2028, and (d) in Dec-Feb in 2044-2045.

years band SST anomalies in Nino3.4 region from 1950 to 2007. The correlation coefficient between the simulated SSTA and Reynolds SSTA in the 2-7 years band is 0.913 , which shows a near-perfect match between the simulated and the observed SST variabilities at the 2-7 years band. This suggests that the model was able to accurately simulate the interannual variability in the tropical ocean. Besides, as suggested by Liu [33], the simulated tropical ocean circulation around the GMR under the NCEP forcing is simulated using the downscaled four-level HYCOM model. Model results were compared with data taken during four oceanographic cruises during 2005-2006 (March 2005, November/December 2005, June/July 2006, and November 2006). The results show that the ocean circulation around GMR is quite consistent with the observation cruise results. These simulations provide a validation for the high-resolution HYCOM model and a benchmark for assessing future AGW impacts.

3.2. The Impact of Future AGW on the Ocean Variability around the GMR. The response of the GMR ocean circulation to future AGW in the next fifty years is simulated using the monthly IPCC-AR4 SRES A1B Emissions scenario from 2001-2050 as the atmospheric forcing (Expt 2), with the goal to better understand the impact of global climate change on the ocean circulation and water mass structure around the GMR region. Figure 5 shows the simulated SST in the Nino3.4 region from 2001 to 2050 forced by IPCC-AR4 SERS A1B atmospheric forcing using HYCOM model, merged with the simulated SST from 1950-2007 presented in Section 3.1. The results indicate that the ocean variability is greatly affected by global climate change. There is a $2^{\circ} \mathrm{C}$ rising trend in the SST anomaly in the Nino3.4 region during the fifty years (2001-2050). During the overlapping years of 20012007 for Expt 1 and Expt 2, the SST in the Nino3.4 region is consistent. The wavelet power spectrum of the simulated SSTA in the Nino3.4 region from 1950 to 2050 (Figure 6) shows that there is an obvious ENSO period of center at approximately $5 \mathrm{yr}$ and a Pacific Decadal Oscillation (PDO) period of approximately $8-10 \mathrm{yr}$. Power spectrum analysis shows that the frequency for the occurrence of ENSO events 


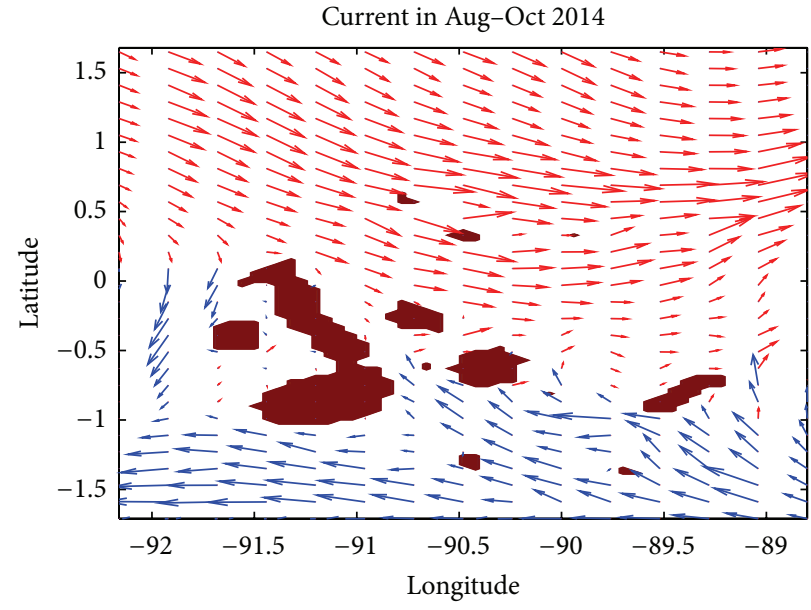

(a)

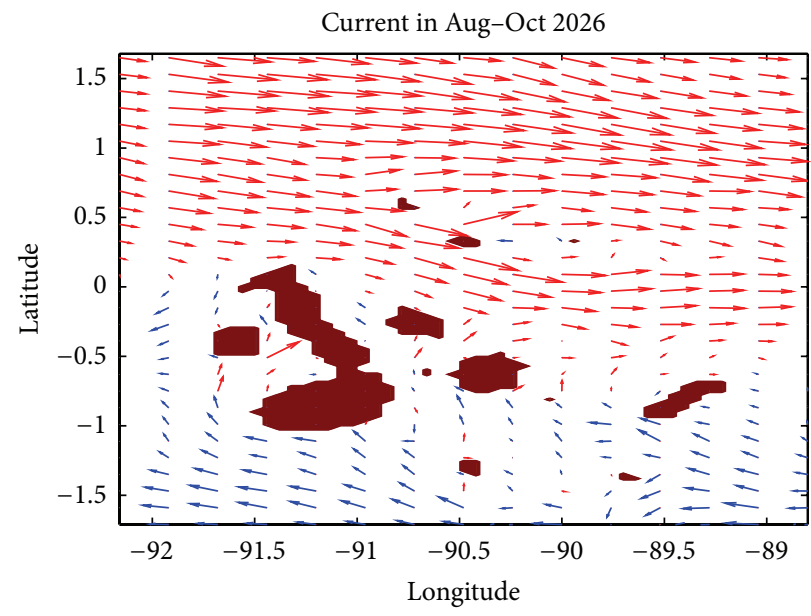

(c)

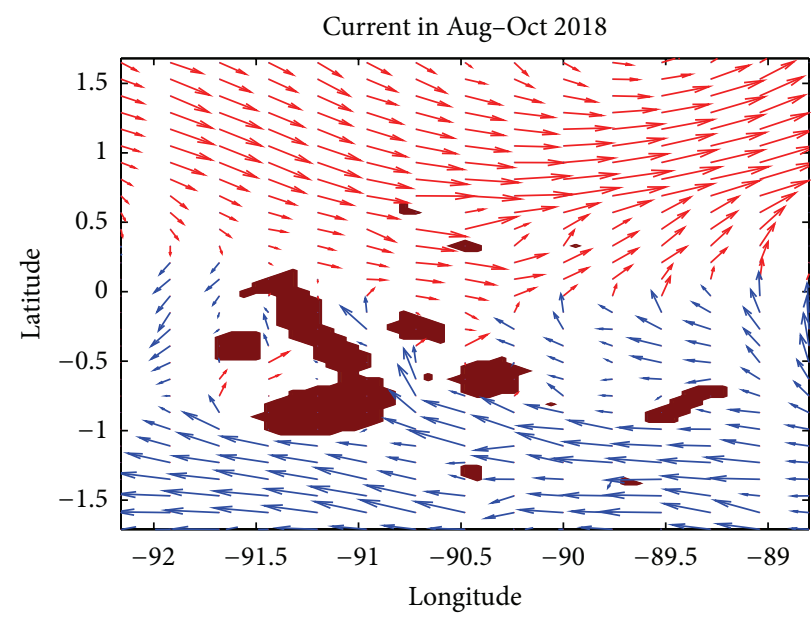

(b)

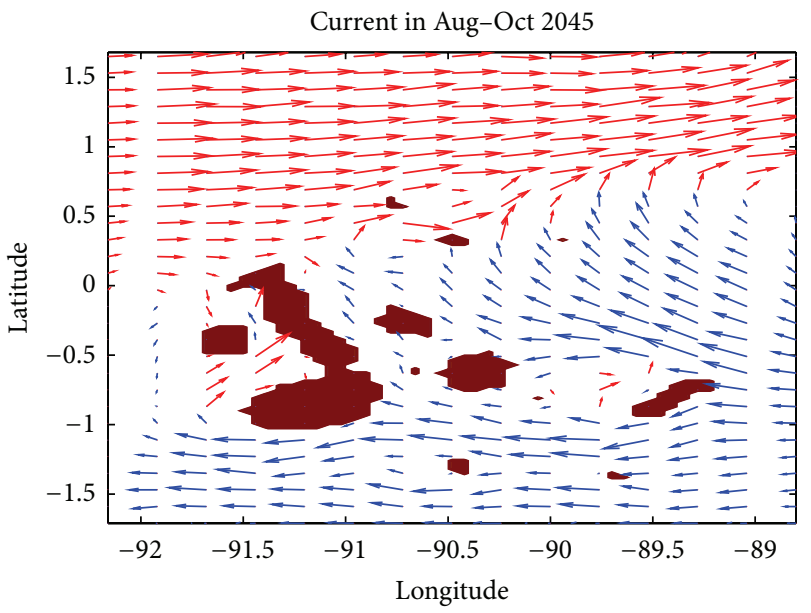

(d)

Figure 12: The surface current around the GMR during the La Niña cases: (a) in Aug-Oct in 2014, (b) in Aug-Oct in 2018, (c) in Aug-Oct in 2026, and (d) in Aug-Oct in 2045.

seems unchanged (4-5 yr) by climate change. Superimposed on top of the interannual variability, there is an increasing SST trend, which may suggest a warmer mean state of the eastern Pacific Ocean, perhaps due to a weaker Walker Circulation. The latter can be diagnosed by an index of the large-scale tropical Indo-Pacific SLP gradient $(\triangle$ SLP, the difference in sea level pressure anomalies averaged in the region $\left(80^{\circ} \mathrm{E}-160^{\circ} \mathrm{E}\right.$, $\left.5^{\circ} \mathrm{S}-5^{\circ} \mathrm{N}\right)$ with those averaged in the region $\left(160^{\circ} \mathrm{W}-80^{\circ} \mathrm{W}\right.$, $\left.5^{\circ} \mathrm{S}-5^{\circ} \mathrm{N}\right)$ ) as a proxy for the mean intensity of the Pacific Walker circulation [34, 35]. Figure 7 shows the evolution of the difference of the sea level pressure anomaly $(\triangle \mathrm{SLP})$ between the East $\left(80^{\circ} \mathrm{E}-160^{\circ} \mathrm{E}, 5^{\circ} \mathrm{S}-5^{\circ} \mathrm{N}\right)$ and the West Pacific $\left(160^{\circ} \mathrm{W}-80^{\circ} \mathrm{W}, 5^{\circ} \mathrm{S}-5^{\circ} \mathrm{N}\right)$ and zonal wind stress anomaly in the Equatorial Pacific $\left(120^{\circ} \mathrm{E}-70^{\circ} \mathrm{W}, 5^{\circ} \mathrm{S}-5^{\circ} \mathrm{N}\right)$ since the 20 th century from the IPCC-AR4 data. There is a rapid reduction in the $\triangle$ SLP, and this reduction since the 20th century is statistically significant at $P=0.05$. In keeping with the change in SLP, the equatorial wind stress also weakened from the 20th century. Because wind stress plays an important role for the large-scale ocean circulation in equatorial Pacific, the weakening of the equatorial wind stress anomaly will result in a weakening of surface equatorial currents and a reduction in the intensity and depth of equatorial upwelling, which can subsequently result in a possible reduction of biological productivity under global warming. Figure 8 shows the simulated SST anomalies depicted by the band-pass filtered SSTA. Future El Niño/La Niña events are clearly indicated. For example the El Niño events in 2013, 2017, 2027, 2030, 2040, 2044 and the La Niña events in 2014, 2018, 2026, 2031, 2041, and 2045 are clearly shown.

3.3. Case Studies. In this section, we will consider the spatial details of the ocean circulation in the Galápagos region during El Niño and La Niña years from 2001 to 2050. The December-February time period is chosen to represent the El Niño season and the August-October for the La Niña season. The El Niño cases include 2013-2014, 2017-2018, 2027-2028, and 2044-2045 El Niño events and the La Niña cases include 2014, 2018, 2026, and 2045 La Niña events. Figures 9 and 10 indicate the SST around the GMR during 


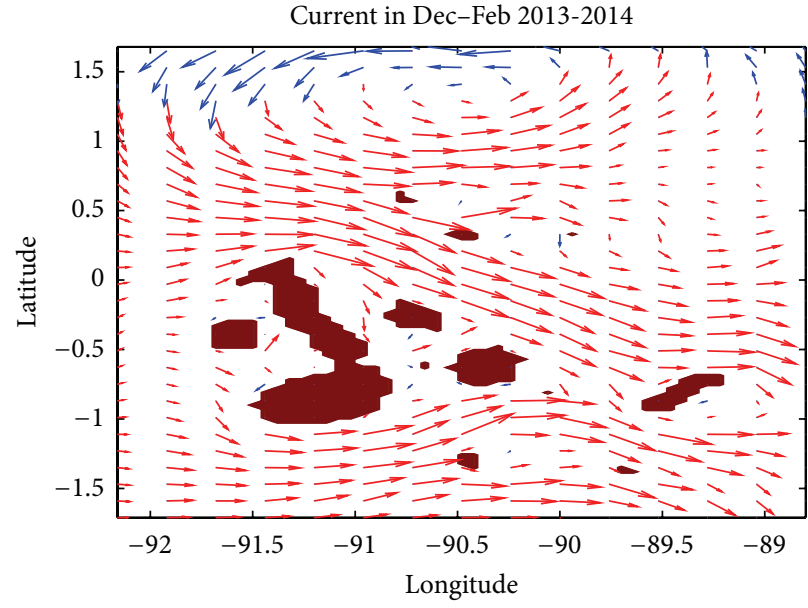

(a)

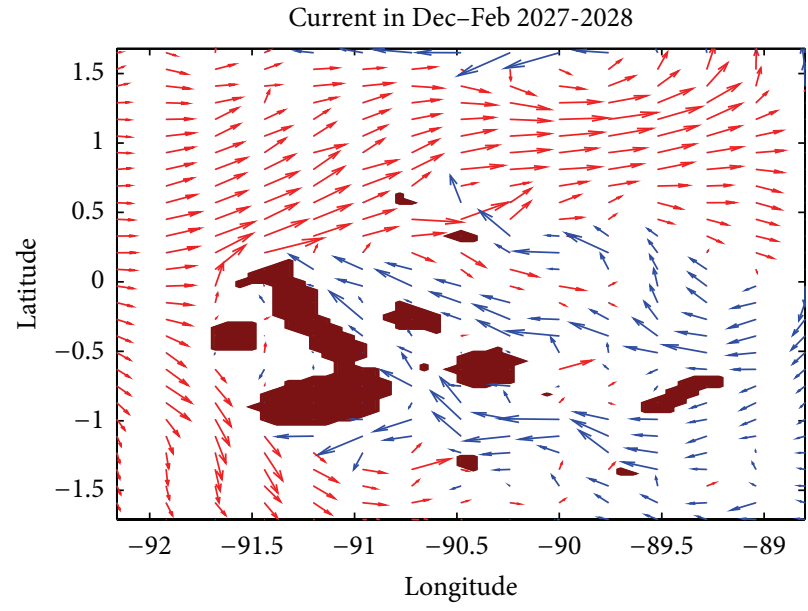

(c)

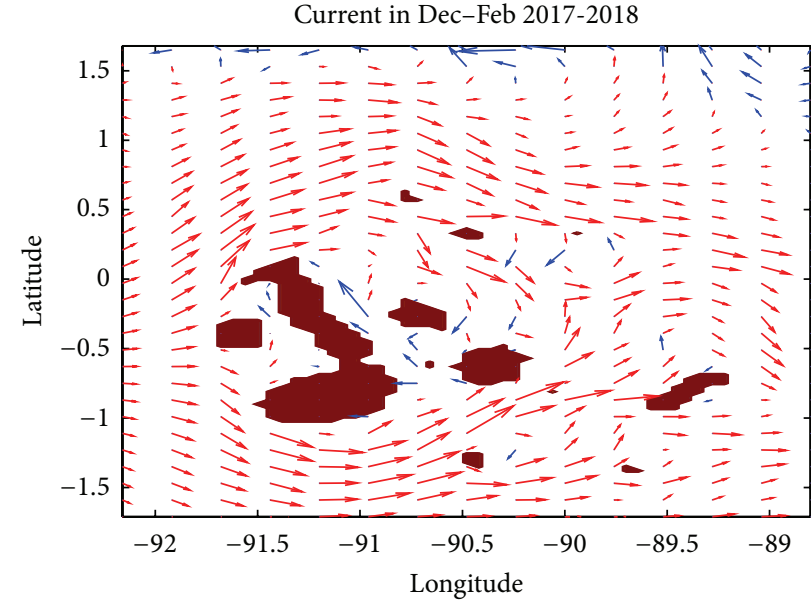

(b)

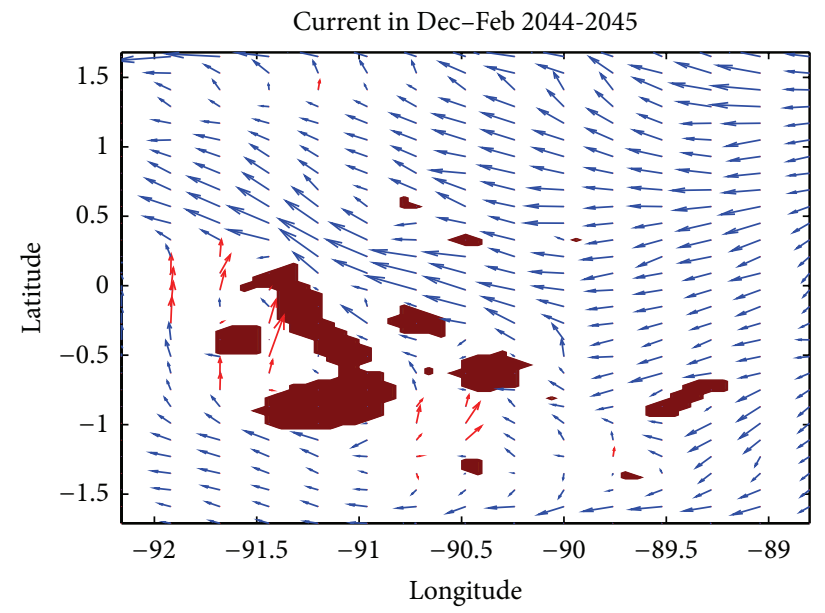

(d)

Figure 13: The current at $40 \mathrm{~m}$ around the GMR during the El Niño cases: (a) in Dec-Feb in 2013-2014, (b) in Dec-Feb in 2017-2018, (c) in Dec-Feb in 2027-2028, and (d) in Dec-Feb in 2044-2045.

the El Niño cases (Figure 9) and La Niña cases (Figure 10), respectively. During the El Niño events, there are warm and less salty waters around the whole GMR region, while less warm and saltier water are found west of Isabella and Fernandina, indicative of a reduction in topographically induced upwelling by the EUC. During the La Niña event, there are cold and salty waters around the whole GMR region, while colder water and saltier water are found west of Isabella and Fernandina, indicative of an increase in topographically induced upwelling by the EUC. Figures 11 and 12 show the surface current around the GMR during the El Niño cases and the La Niña cases, respectively. Figures 13 and 14 show the currents in the mixed layer around the GMR during the El Niño cases and the La Niña cases, respectively. During the El Niño events, the surface currents during this period were dominated by the westward flowing SEC. The EUC was greatly weakened, leading to weaker upwelling to the west of Isabella Island. During the La Niña cases, the westward flow of the SEC is collided with the eastward flow of the EUC both north and south of Isabella Island.
Figures 15 and 17 show the vertical sections of the zonal current along $92^{\circ} \mathrm{W}, 91.8^{\circ} \mathrm{W}, 90^{\circ} \mathrm{W}$, and $89^{\circ} \mathrm{W}$ for the upper $200 \mathrm{~m}$ around the GMR in the Dec-Feb 2014 El Niño event and the Aug-Oct 2014 La Niña event. Figures 16 and 18 show the vertical sections of zonal current $\left(\mathrm{m} \mathrm{s}^{-1}\right)$ along $1^{\circ} \mathrm{S}, 0.5^{\circ} \mathrm{S}$, $\mathrm{EQ}$, and $0.5^{\circ} \mathrm{N}$ for the upper $200 \mathrm{~m}$ around the GMR in the Dec-Feb 2014 El Niño event and the Aug-Oct 2014 La Niña event. These results also show that during El Niño, the EUC will be greatly weakened, leading to a weaker upwelling to the west of Isabella Island. While during La Niña, the EUC will be greatly strengthened and even reach the sea surface. The EUC core is located around $0.5^{\circ} \mathrm{N}$. During El Niño, the SEC is diminished in strength during its respective annual cycle, as is the EUC, whose core also sinks tens of meters, in keeping with the finding of Johnson et al. [36]. In addition, a decreased Ekman divergence and evaporation [37] and eastward migration of the warm SST pool contribute to a reduced upwelling and warming of the SST consistent with the results of Fiedler and Talley [38]. The opposite response occurs during La Niña. The surface salinity changes little as 


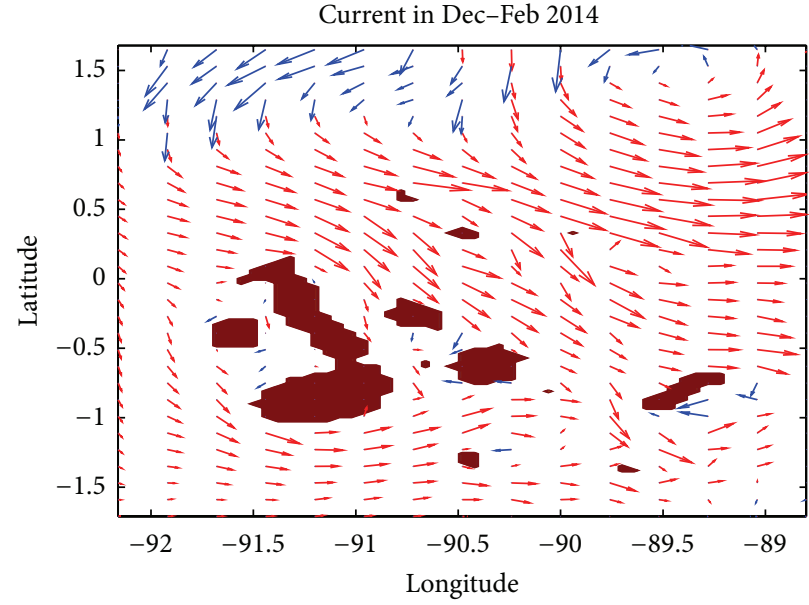

(a)

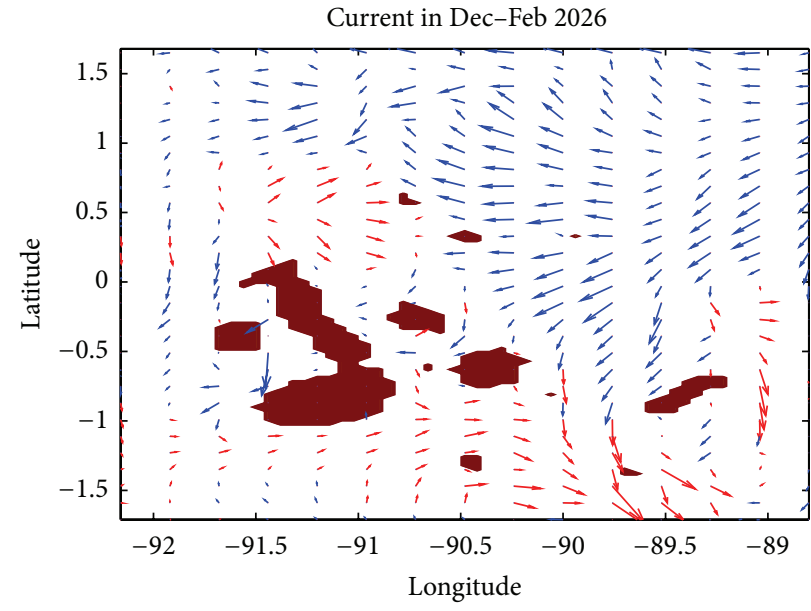

(c)

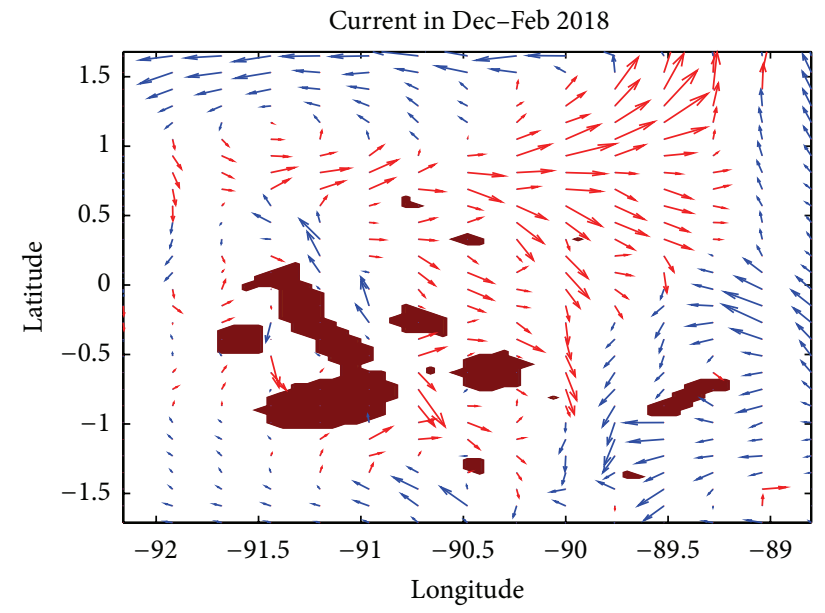

(b)

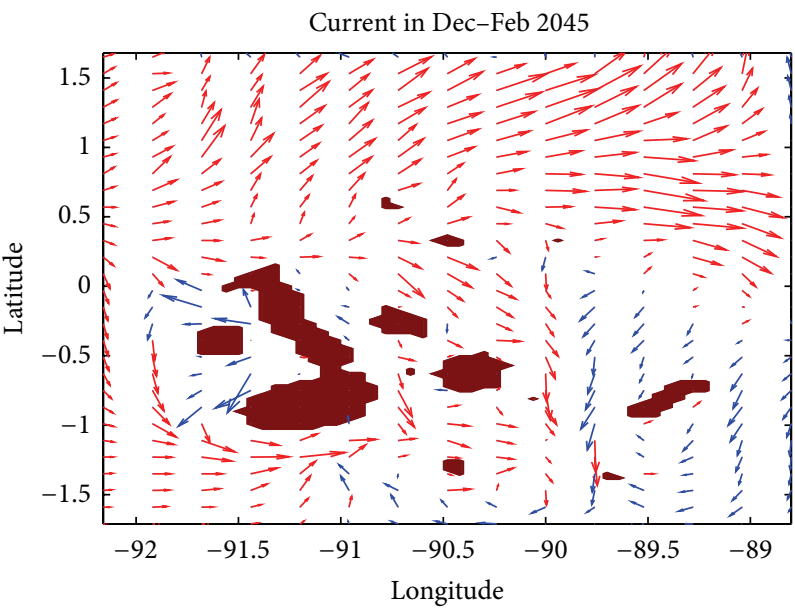

(d)

FIGURE 14: The current at $40 \mathrm{~m}$ around the GMR during the La Niña cases: (a) in Dec-Feb in 2013-2014, (b) in Dec-Feb in 2017-2018, (c) in Dec-Feb in 2027-2028, and (d) in Dec-Feb in 2044-2045.

shown by Fiedler and Talley [38], with a marginal decrease (increase) during El Niño (La Niña) as upwelling within the equatorial cold tongue is slightly suppressed (heightened).

Although El Niño leads to a general warming and La Niña a general cooling of sea surface water in the GMR region, there is clearly a spatial difference in the degree of warming. To illustrate the difference of SST changes at different spatial and temporal scales, the SST trends are computed at each grid point in the GMR region and plotted. Figures 19(a)-19(e) show the grid-by-grid trend of SST at different time scales from 10 to 30 years: (a) $10 \mathrm{yr}$ from 2005-2014, (b) $15 \mathrm{yr}$ from 2005-2019, (c) 20 yr from 2005-2024, (d) 25 yr from 20052029, and (e) $30 \mathrm{yr}$ from 2005-2029. The positive (negative) values in the plot indicate positive (negative) local trend in the region for the corresponding time period. The presence of different values and signs in the trend field indicates that SST values in the GMR region show inhomogeneous trends in different regions and for different time periods.

As shown in Figure 19, the warming trend in this upwelling zone to the west of Galápagos is clearly smaller than other regions. For the 10-year and 15-year SST trends, the trend in this region is even marginally negative, suggesting a slight cooling around most of the GMR region, especially in the upwelling zone. However, at longer time periods (2030 years), the trend is upward, suggesting broad warming in the region. In summary, the regional impact of global climate change in the Galápagos regions varies from region to region. The SST trend is dependent on both location and time period. The upwelling region has the lowest warming trend and experiences a slight cooling trend at 10-15 years time scales. This indicates that in the near term, the upwellingzone may be less affected by global warming compared with other regions of the GMR.

\section{Study of the EUC Using TAO Moored Data and Model Data}

4.1. Definitions of EUC Time Series from TAO/TRITON Data and Numerical Model. In this section, we will analyze the impact of the complex current systems in eastern equatorial Pacific on the SST variability in the GMR region with a goal to understand the reasons for the simulated 


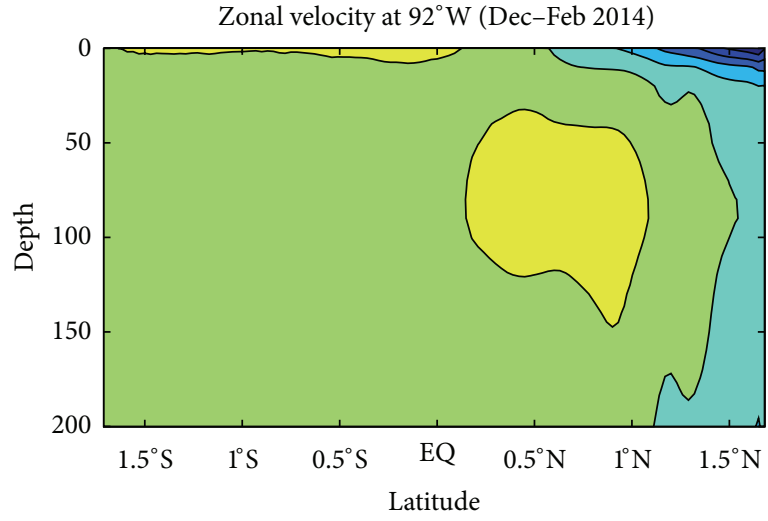

(a)

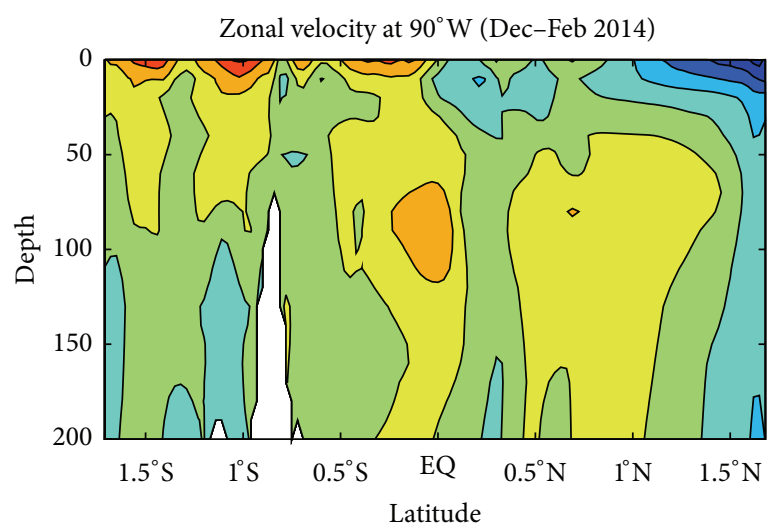

(c)

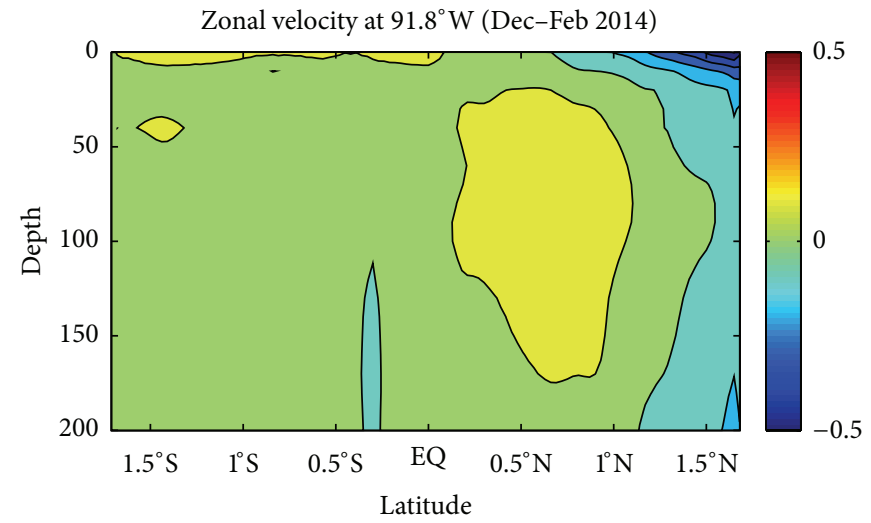

(b)

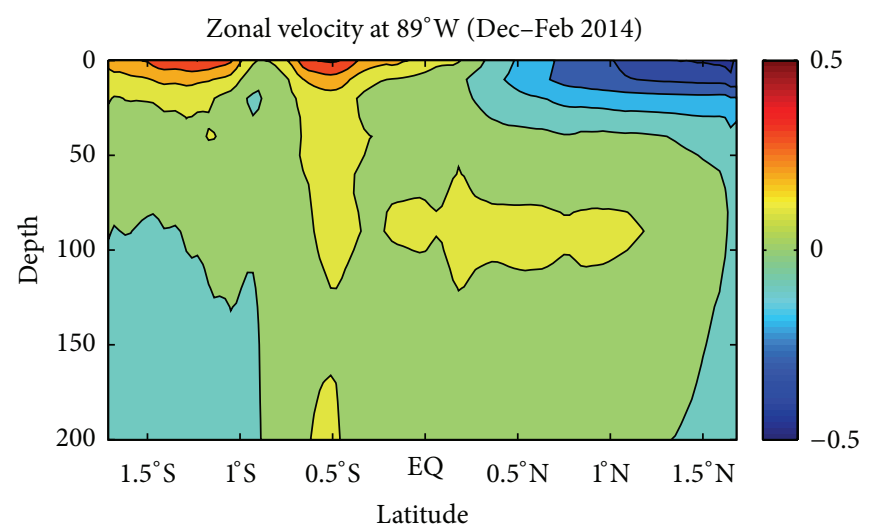

(d)

Figure 15: Vertical sections of zonal current $\left(\mathrm{m} \mathrm{s}^{-1}\right)$ along $92^{\circ} \mathrm{W}, 91.8^{\circ} \mathrm{W}, 90^{\circ} \mathrm{W}$, and $89^{\circ} \mathrm{W}$ for the upper $200 \mathrm{~m}$ around the GMR in Dec-Feb 2014 El Niño event.

spatially inhomogeneous SST trends. The CTD/ADCP data are used to calculate the EUC volume flux transport during Tropical Atmosphere-Ocean/Triangle Trans-Ocean Buoy Network (TAO/TRITON) buoy array cruises, which is an ocean observing system of instrumented moorings spanning the entire equatorial Pacific for monitoring seasonal-tointerannual climate variability [39]. The TAO/TRITON array consists of approximately 70 moorings between $170^{\circ} \mathrm{W}$ and $95^{\circ} \mathrm{W}$ which measure subsurface temperature. At some locations, current meters and acoustic Doppler current profiler (ADCP) measurements are also available. To study the EUC volume flux, we use the currents from TAO moorings along the equator at $140^{\circ} \mathrm{W}$ and at $110^{\circ} \mathrm{W}$ from 2001 to 2007 .

In the calculation of volume fluxes using the data from the TAO moorings, the EUC is defined as the zonal currents $(U)$ which satisfy the following criteria: $U>0 \mathrm{~m} \mathrm{~s}^{-1}$ and $25 \mathrm{~m}<z<300 \mathrm{~m}$ (or less depending on data availability). The sensitivity to the choice of the criteria was tested and appeared insignificant for the variability of EUC volume flux. The mean transport of EUC is defined as

$$
U_{\mathrm{EUC} / \mathrm{eq}}=\int_{\mathrm{EUC}} u d z
$$

where $U_{\mathrm{EUC} / \mathrm{eq}}$ is the volume transport per unit width in $\mathrm{m}^{2} \mathrm{~s}^{-1}$ obtained by integrating the zonal current at the equator over all depth where EUC is defined. The SEC is defined similar to EUC but with zonal current $U<0$.

In the HYCOM model, the same criteria are used to define the EUC and SEC. Because the high-resolution model domain does not include $95^{\circ} \mathrm{W}$, for convenience, the simulated EUC volume flux at $140^{\circ} \mathrm{W}$ and $110^{\circ} \mathrm{W}$ is computed using the simulated currents from the $0.72^{\circ} \times 0.36^{\circ}$ domain. In the model, there is a proportionality between the zonal current integrated only vertically right at the equator over the depth of EUC $\left(U_{\mathrm{EUC} / \mathrm{eq}}\right)$ and the currents integrated over the whole EUC section $\left(U_{\mathrm{EUC}}\right)$. For a better comparison, we use a meridional width $L$ of about $100 \mathrm{~km}$. $U_{\mathrm{EUC}}=L *$ $U_{\mathrm{EUC} / \mathrm{eq}}$. Figure 20 shows the comparison between the model and the TAO EUC (SEC) volume flux transport at $140^{\circ} \mathrm{W}$ and $110^{\circ} \mathrm{W}$, which indicate that the simulated EUC volume flux transport is consistent with the TAO array observations, especially with respect to the annual/interannual cycle. This indicates that the constructed EUC/SEC time series obtained from the in situ data from 2001-2007 could be used to study the EUC variability and validate the simulated EUC. In the next section, we will use the ocean model to study the EUC in more details. 


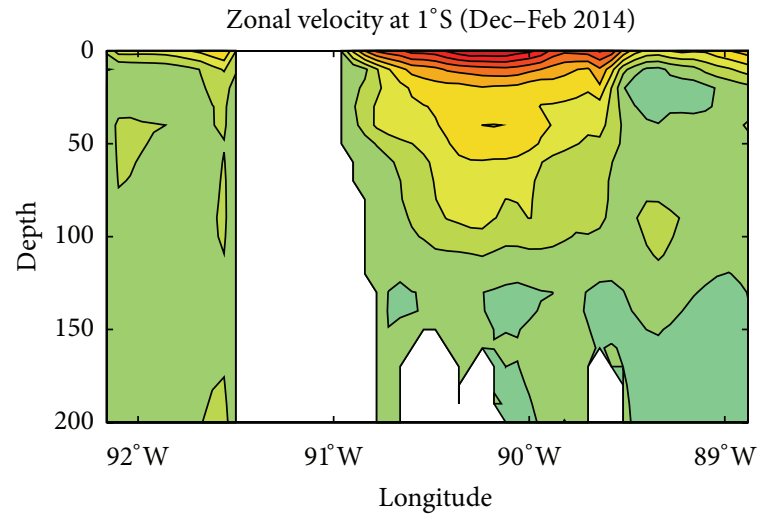

(a)

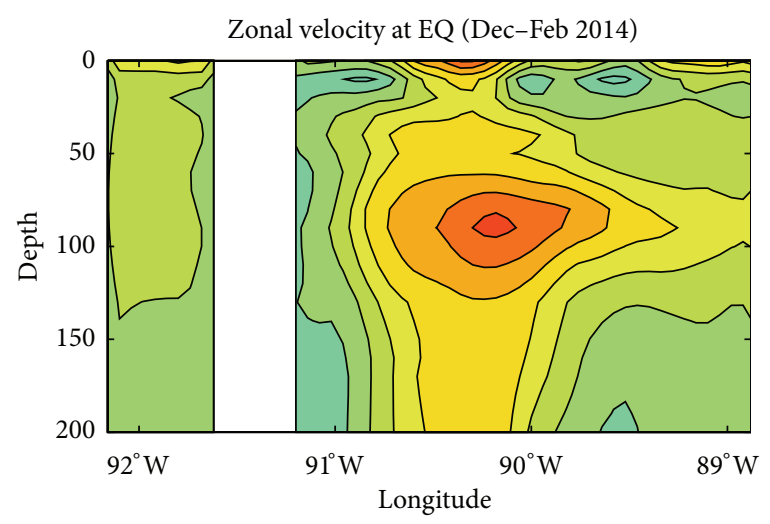

(c)

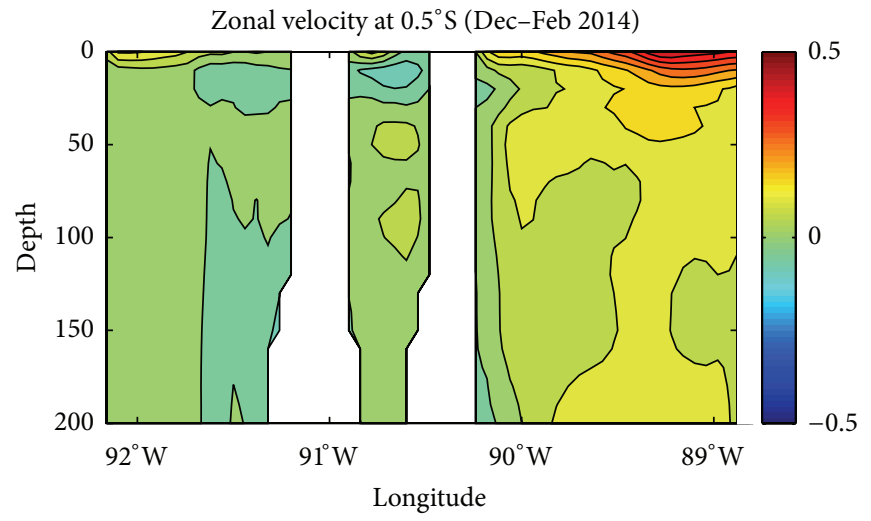

(b)

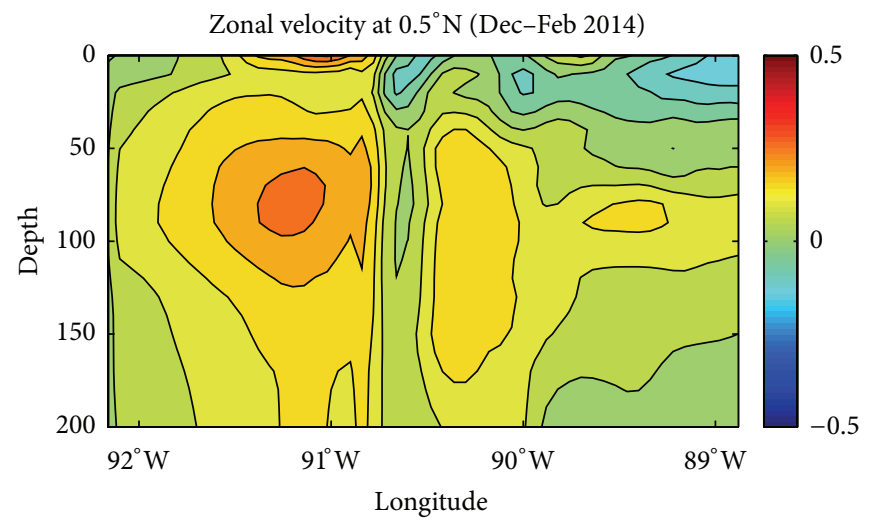

(d)

FIGURE 16: Vertical sections of zonal current $\left(\mathrm{m} \mathrm{s}^{-1}\right)$ along $1^{\circ} \mathrm{S}, 0.5^{\circ} \mathrm{S}$ equator and $0.5^{\circ} \mathrm{N}$ for the upper $200 \mathrm{~m}$ around the GMR in Dec-Feb 2014 El Niño event.

4.2. Study of EUC Using Numerical Model (HYCOM). Because of the scarcity of current data, the numerical model (HYCOM) is used to study the EUC/SEC volume flux variability and the effect of the three main regional current systems on the oceanographic variability in different regions of the Galápagos. Figure 21 shows the simulated EUC, SEC (including Panama current and Peru current) volume flux transport from 2005 to 2035 around GMR. The solid line is the simulated flux transport computed using the simulated currents from the high-resolution $\left(0.06^{\circ} \times 0.03^{\circ}\right)$ domain, while the dashed line represents the flux transport computed using the simulated currents from the relatively low-resolution $\left(0.72^{\circ} \times 0.36^{\circ}\right)$ domain. For the low-resolution domain, we defined the EUC as $U>0 \mathrm{~ms}^{-1}$ and $0 \mathrm{~m}<$ $z<300 \mathrm{~m}$ and defined the EUC volume flux transport per unit width in $\mathrm{m}^{2} \mathrm{~s}^{-1}$ obtained by integrating the zonal current over the whole EUC section between $3^{\circ} \mathrm{S}$ and $3^{\circ} \mathrm{N}$ over all depth where EUC is defined. The SEC is defined similar to EUC but for $U<0 \mathrm{~ms}^{-1}$. It consists of the Panama current and the Peru current. The Panama current is defined by $U<0 \mathrm{~m} \mathrm{~s}^{-1}$ and $V<0 \mathrm{~ms}^{-1}$, while the Peru current is defined by $U<0 \mathrm{~ms}^{-1}$ but $V>0 \mathrm{~m} \mathrm{~s}^{-1}$. In the high resolution domain, because of the limitation of the domain size $\left(92.16^{\circ} \mathrm{W}-88.74^{\circ} \mathrm{W}, 1.71^{\circ} \mathrm{S}-1.71^{\circ} \mathrm{N}\right)$, we can only define the portions of EUC/SEC within the domain $\left(1.71^{\circ} \mathrm{S}\right.$ $\left.1.71^{\circ} \mathrm{N}\right)$. All the simulated volume flux transport within the high-resolution domain is smaller than that under the low resolution simulation due to the difference in covered area. The correlation coefficient of the EUC volume flux transport between those two resolution simulations is 0.793 while the correlation coefficient of Panama current and Peru current between those two resolution simulations is 0.279 and 0.473 , respectively. Due to the domain limitation of the highresolution simulations, we will use the simulated volume flux transport computed from the low resolution of $0.72^{\circ} \times 0.36^{\circ}$ domain in following discussions.

To determine how various current systems are related to each other, the correlation coefficients between the three major currents in the region (EUC versus Peru, EUC versus Panama and Panama versus Peru) are calculated. The results show that the correlation coefficient between the Panama (Peru) current volume flux and EUC current volume flux is 0.241 (0.192), respectively. Both pass the $95 \%$ significance test, while the correlation coefficient between the Panama current and Peru current is only 0.016. This indicates that the Panama current and Peru current are significantly correlated with the EUC current, while the Panama current is not related to Peru current. 


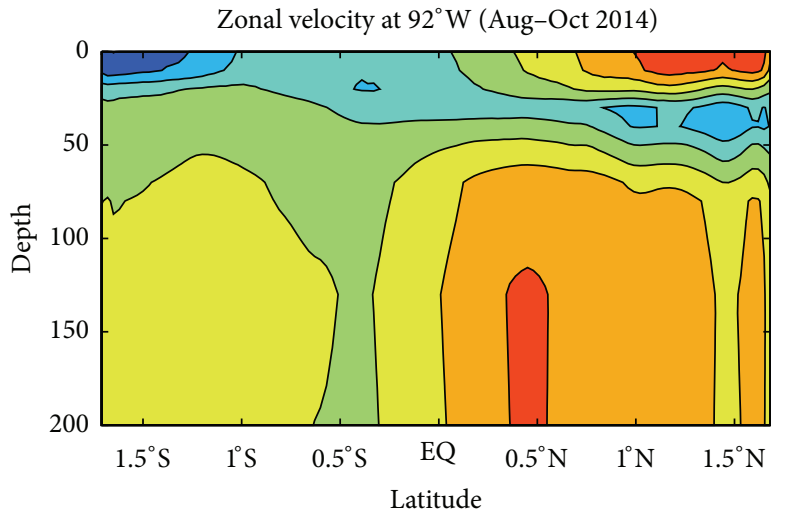

(a)

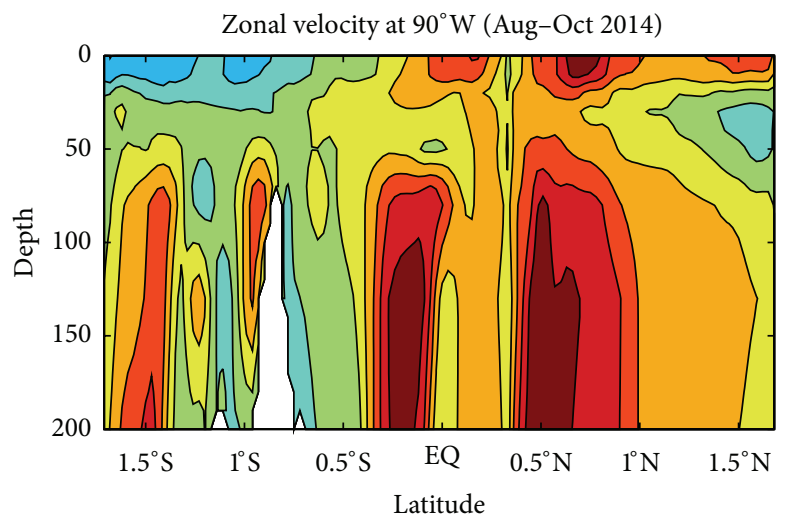

(c)

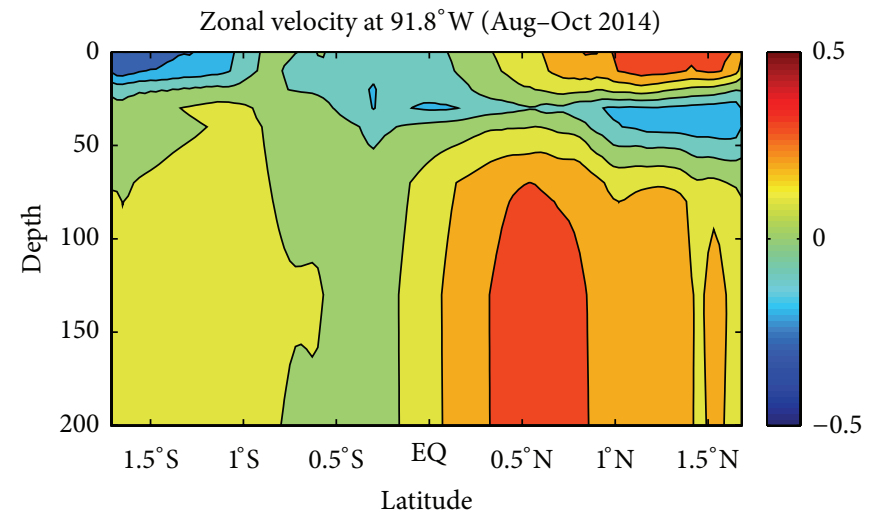

(b)

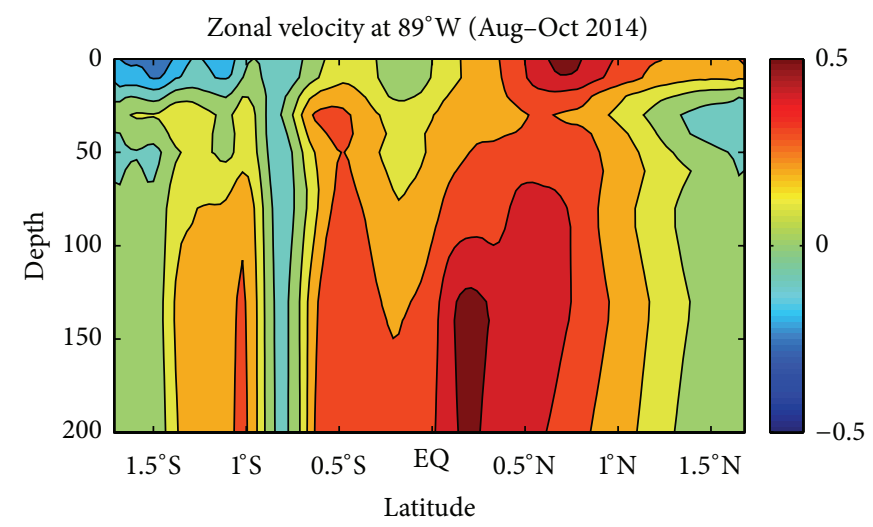

(d)

Figure 17: Vertical sections of zonal current $\left(\mathrm{m} \mathrm{s}^{-1}\right)$ along $92^{\circ} \mathrm{W}, 91.8^{\circ} \mathrm{W}, 90^{\circ} \mathrm{W}$, and $89^{\circ} \mathrm{W}$ for the upper $200 \mathrm{~m}$ around the GMR in Aug-Oct 2014 La Niña event.

The GMR is composed of several regions [40]: the west Galápagos, the far north region, the southeast region, the central region, and so forth. In order to understand the effect of different currents (EUC, Panama and Peru) on the SST variability in different areas of the Galápagos Archipelago, as well as the key region for EUC upwelling, the correlation coefficients between the computed EUC (Panama/Peru Current) volume flux transport and the SST fields in the simulation using the high-resolution $\left(0.06^{\circ} \times\right.$ $0.03^{\circ}$ ) domain are calculated (Figure 22). Figure 22 shows that in most of the Galápagos region, the EUC volume flux is negatively correlated to SST, especially for the west Galápagos upwelling region and central Galápagos, which means that SST is reduced when EUC is strong. For the Panama current, the volume flux is mostly positively correlated to the SST field, especially in the western Galápagos upwelling region and the northeast region, which suggests that SST increases when Panama current is strong. For the Peru Current, the volume flux is negatively correlated to SST, especially in the central Galápagos and southeast regions. In summary, the western Galápagos upwelling region is strongly affected by the EUC and Panama currents, while central/east Galápagos is affected by both Peru and EUC currents. The north region is affected by the Panama current only. The southeast region is affected by Peru current only. These regional differences may explain the variability of the inhomogeneous responses in different regions of the Galápagos Archipelago to global climate change.

\section{Concluding Remarks}

The regional impact of global climate change on the ocean circulation and water mass characteristics around the Galápagos Archipelago is studied using the Hybrid Coordinate Ocean Model (HYCOM). A four-level nested domain system is used in the study to downscale the global climate change impact on the regional scale oceanic variability centered on the Galápagos Archipelago.

The ocean circulation driven by the past and current climate is simulated using HYCOM with daily atmospheric forcing derived from the NCEP/NCAR reanalysis dataset for the period of 1950-2007 (Expt 1) as well as from 2001 to 2050 using atmospheric forcing derived from the IPCC-AR4 SRES A1B scenarios (Expt 2). The results indicate that with prescribed atmospheric forcing from 1950 to 2007, the major characteristics of the ocean circulation and its variability in the Galápagos region, including the ENSO events, annual and seasonal cycles, upwelling system, local and regional current 


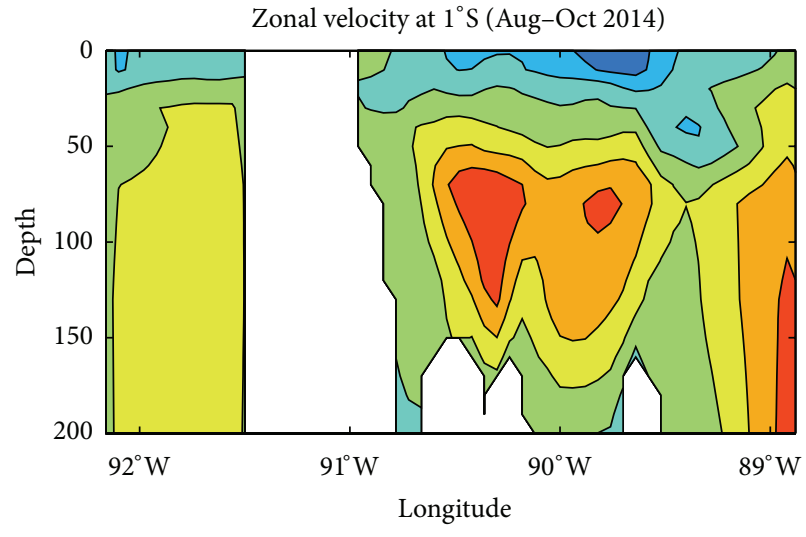

(a)

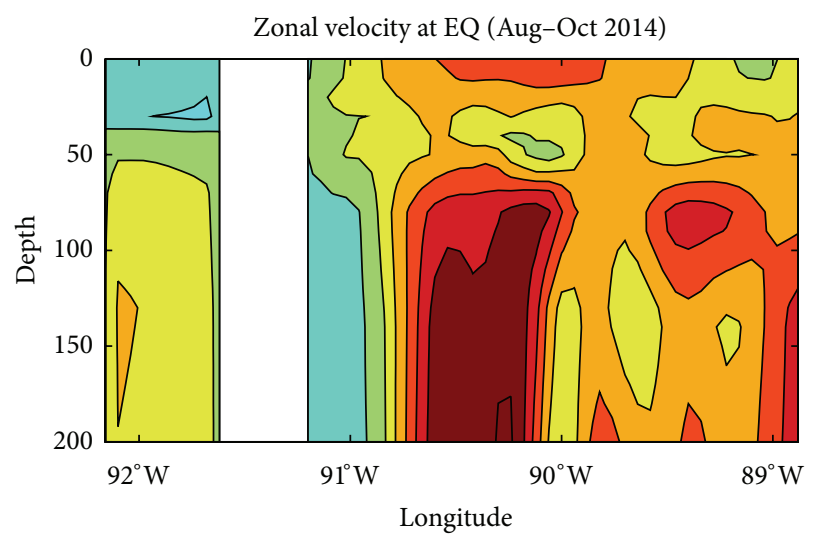

(c)

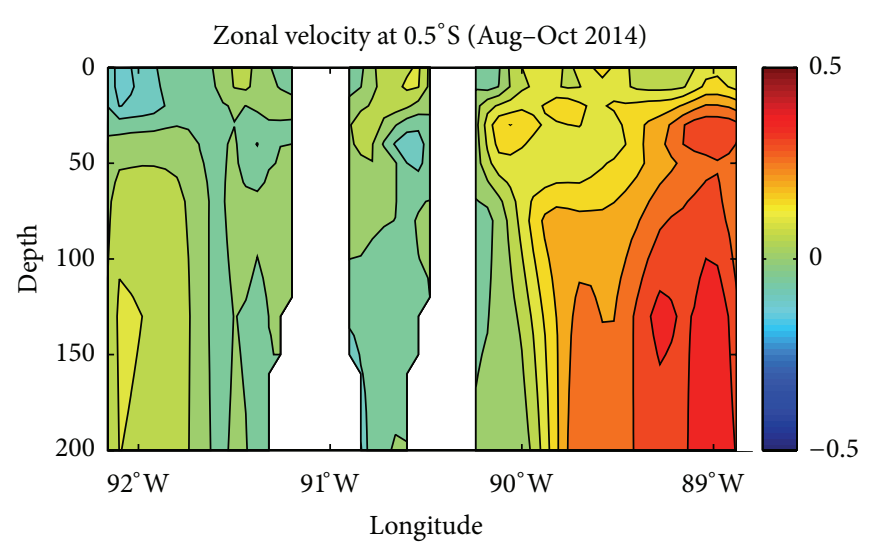

(b)

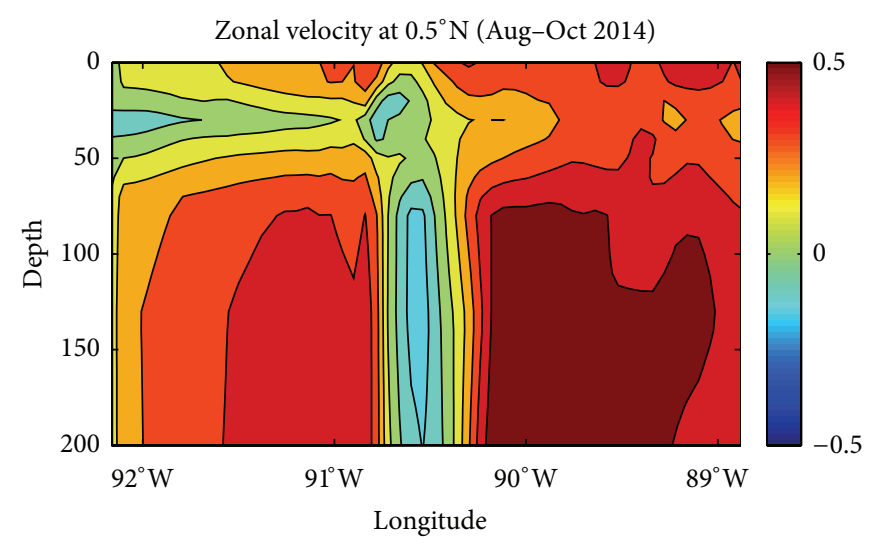

(d)

Figure 18: Vertical sections of zonal current $\left(\mathrm{m} \mathrm{s}^{-1}\right)$ along $92^{\circ} \mathrm{W}, 91.8^{\circ} \mathrm{W}, 90^{\circ} \mathrm{W}$, and $89^{\circ} \mathrm{W}$ for the upper $200 \mathrm{~m}$ around the GMR in Aug-Oct 2014 La Niña event.

systems, and tropical instability waves, can be reproduced by the nested HYCOM. There is a high correlation between the simulated SST anomalies and the observed SST anomalies in the Nino3.4 region. The results from Expt 2 show that the oceanic variability in the Galápagos region is sensitive to global climate change. The result also indicates that future climate will continue the type of El Niño/La Niña phenomenon as seen in the present day climate; however, the presence of a warming trend, at a rate of approximately 0.1-0.4 degrees per decade, creates higher maximum SST during future El Niño than the one seen in the past. There are different characteristics in future ENSO events, with some events shutting down the EUC and the upwelling almost completely within the upper $50 \mathrm{~m}$ of water.

The regional impact of global climate change in the Galápagos region varies from region to region. The upwelling region has the smallest warming trend and is expected to experience a slight cooling at the 10-15 years near term change. This indicates that the upwelling zone to the west of the Galápagos may be more resilient to the impact of anthropogenic global warming compared with other regions.

The volume transport variations in the entire equatorial band of the Pacific and in its eastern part are quantified using both in situ data and HYCOM simulations. The effect of different currents (EUC, Panama and Peru) on the SST variability in different areas of the Galápagos Archipelago is studied. The results show that the western Galápagos upwelling region is affected mainly by the EUC and Panama currents, while central/east Galápagos is predominantly affected by both Peru and EUC currents. The north region is affected by the Panama current only. The southeast region is affected by Peru current only. These regional differences may explain the inhomogeneous responses in different regions of the Galápagos Archipelago to global climate change.

Finally, it is important to point out some of the limitations in this study. Here, our result is based on one IPCC scenario only. A more reliable way to assess regional response to climate change is to estimate the range of responses using ensemble approach. Here, our model results mainly focused on the ocean circulation in the GMR, which do not account for the tidal influence. The inclusion of tides is also important for the future study since the dynamics within the islands are essentially the same as those in a coastal environment; therefore the tides can have important implications regarding larval dispersal [41]. Further research is also required on the ecosystem-based responses to climate changes in the GMR. This study will also benefit from the development of regional coupled atmosphere-ocean models. 


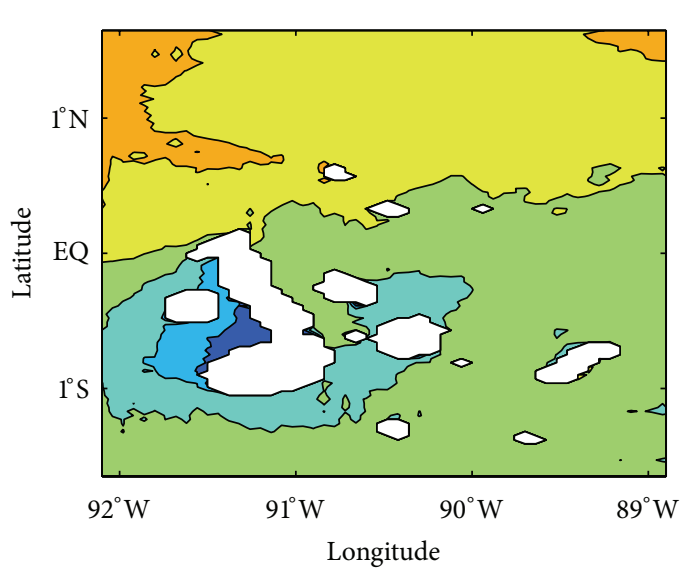

(a) SST trend for $2005-2014$

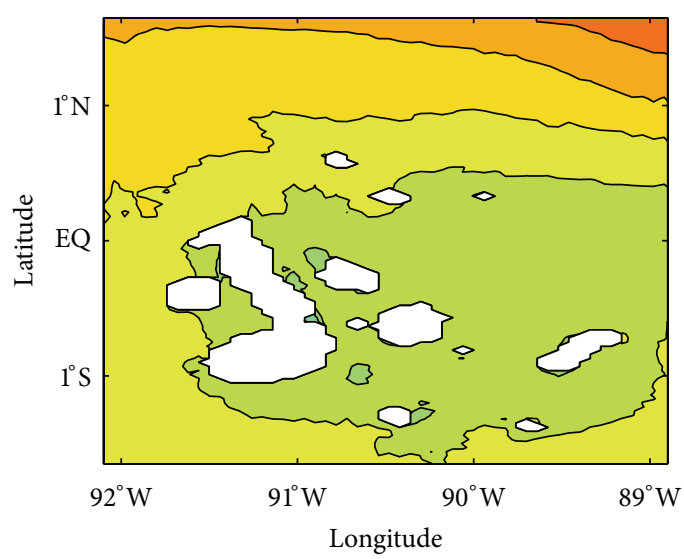

(c) SST trend for 2005-2024
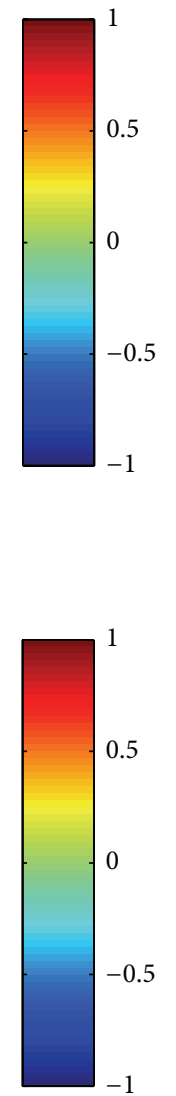

$9^{\circ} \mathrm{W}$

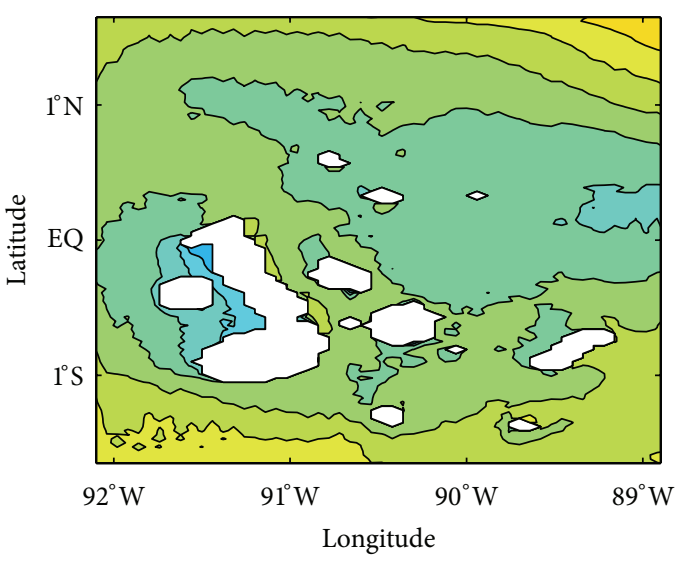

(b) SST trend for 2005-2019

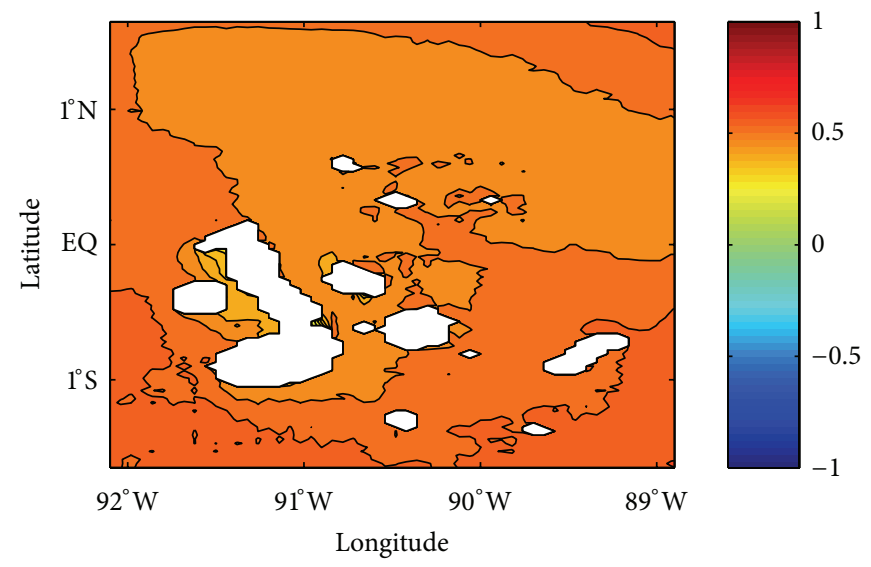

(d) SST trend for 2005-2029
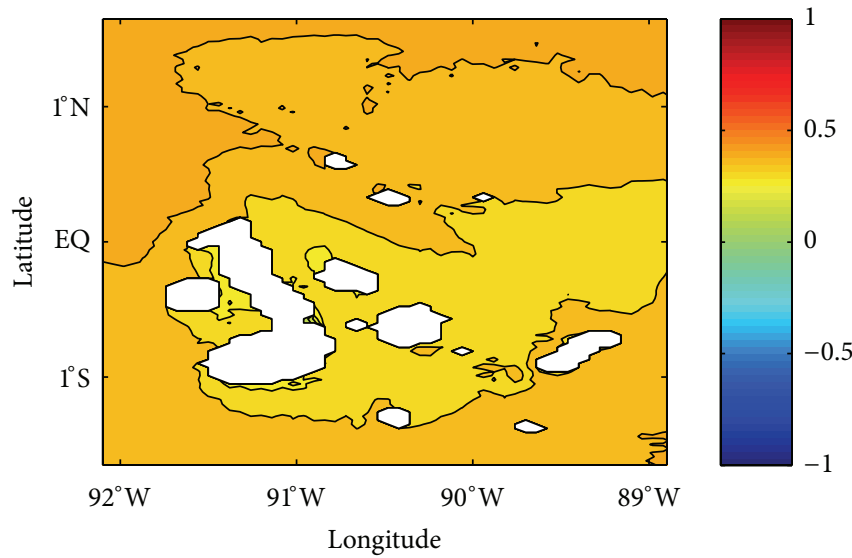

(e) SST trend for 2005-2034

Figure 19: The SST trend contour around GMR for (a) $10 \mathrm{yr}$ from 2005-2014, (b) $15 \mathrm{yr}$ from 2005-2019, (c) 20 yr from 2005-2024, (d) 25 yr from 2005-2029, and (e) $30 \mathrm{yr}$ from 2005-2029.

\section{Acknowledgments}

The authors would like to thank Dr. Bin Liu and two anonymous reviewers for their thoughtful comments and suggestions, which led to a significant improvement of the paper. They thank Dr. Rainer Bleck and Dr. Alan Wallcraft for the help with the HYCOM model. They thank Dr. Jili Dong for the help with the figures. This project was funded by the
National Aeronautics Space Association (NASA) Biodiversity and Ecological Forecasting Grant NNG04GL98G. The Counterpart US-AID no. 518-A-00-03-00152-00 and UK Darwin Initiative Project no. 14-048 also provided funding for this project. The technical support and computer resource from the National Center for Atmospheric Research (NCAR/CISL) are also appreciated. The modeling work is carried out in the Coastal Fluid Dynamical Lab of North Carolina State 


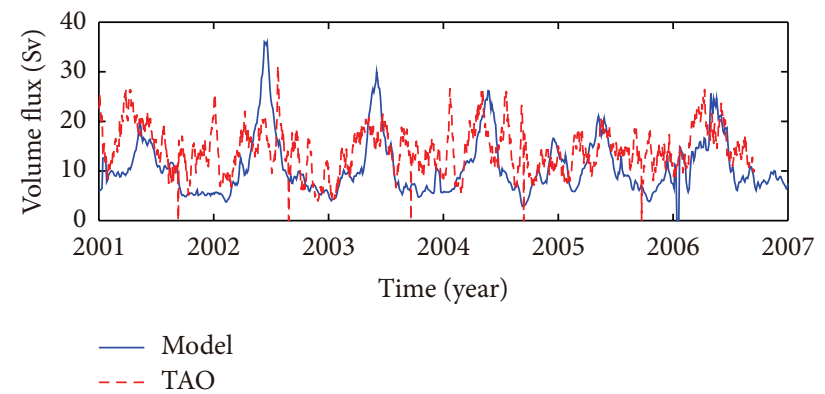

(a) EUC volume flux at $140^{\circ} \mathrm{W}$

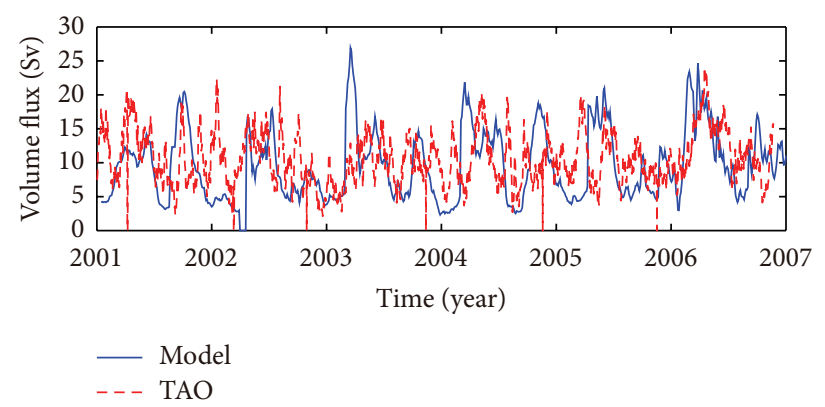

(c) EUC volume flux at $110^{\circ} \mathrm{W}$

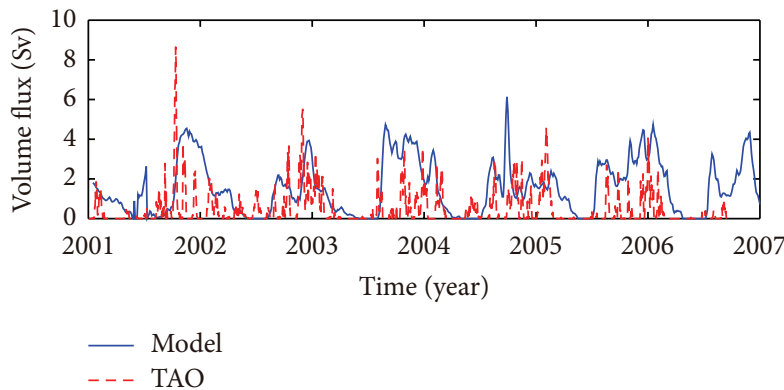

(b) SEC volume flux at $140^{\circ} \mathrm{W}$

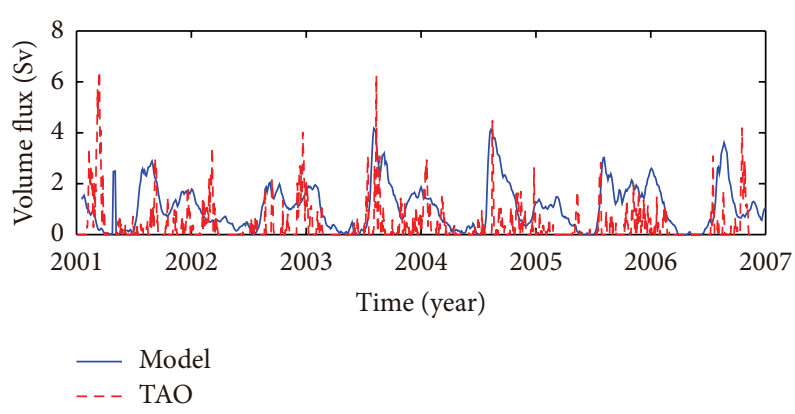

(d) SEC volume flux at $110^{\circ} \mathrm{W}$

FIGURE 20: The compared model and observational EUC (SEC) volume flux transport at $140^{\circ} \mathrm{W}$ and $110^{\circ} \mathrm{W}$, respectively.

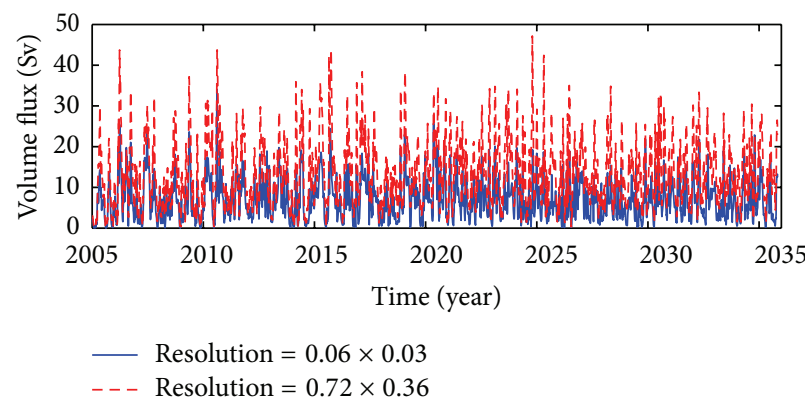

(a) EUC volume flux

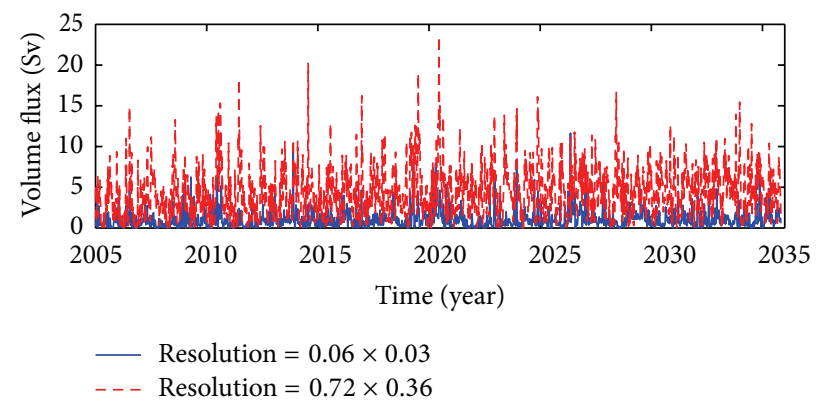

(b) SEC (Panama) volume flux

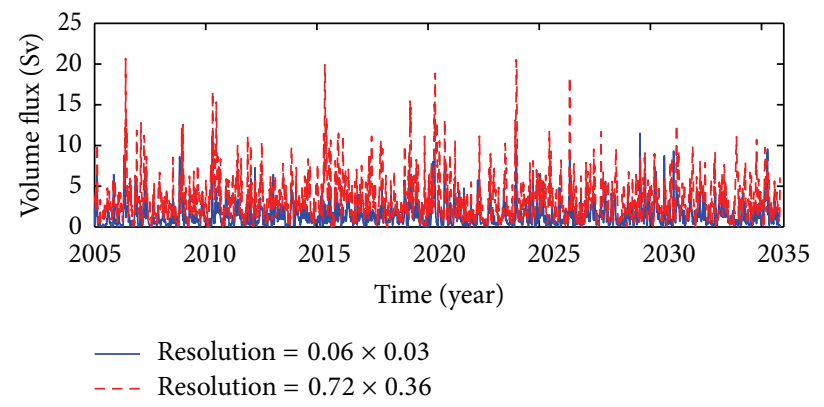

(c) SEC (Peru) volume flux

Figure 21: The simulated EUC, SEC (including the Panama current and the Peru current) volume flux transport from 2005 to 2035 around GMR. The solid line is the simulated flux transport with a high resolution of $0.06^{\circ} \times 0.03^{\circ}$, while the dashed line means the simulated flux transport with a relatively low resolution of $0.72^{\circ} \times 0.36^{\circ}$. 


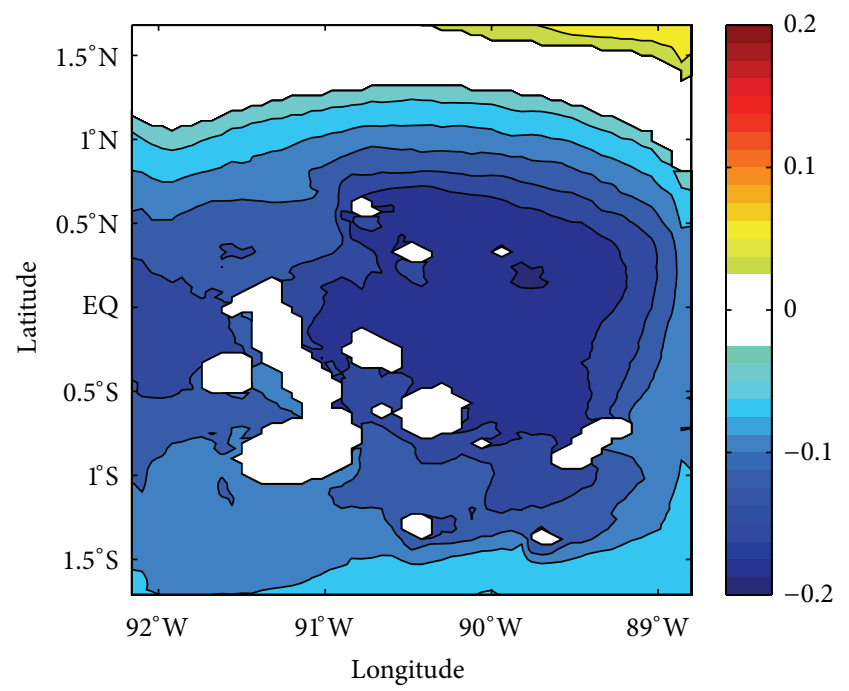

(a) SST and EUC $\left(92^{\circ} \mathrm{W}\right)$ correlation $($ sig $=0.05)$

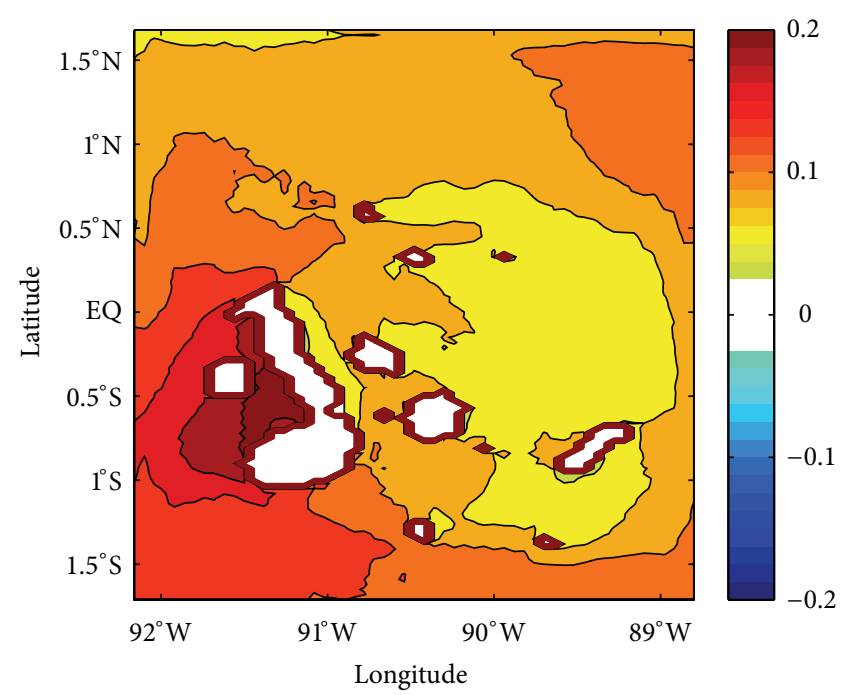

(b) SST and Panama $\left(89^{\circ} \mathrm{W}\right)$ correlation $(\operatorname{sig}=0.05)$

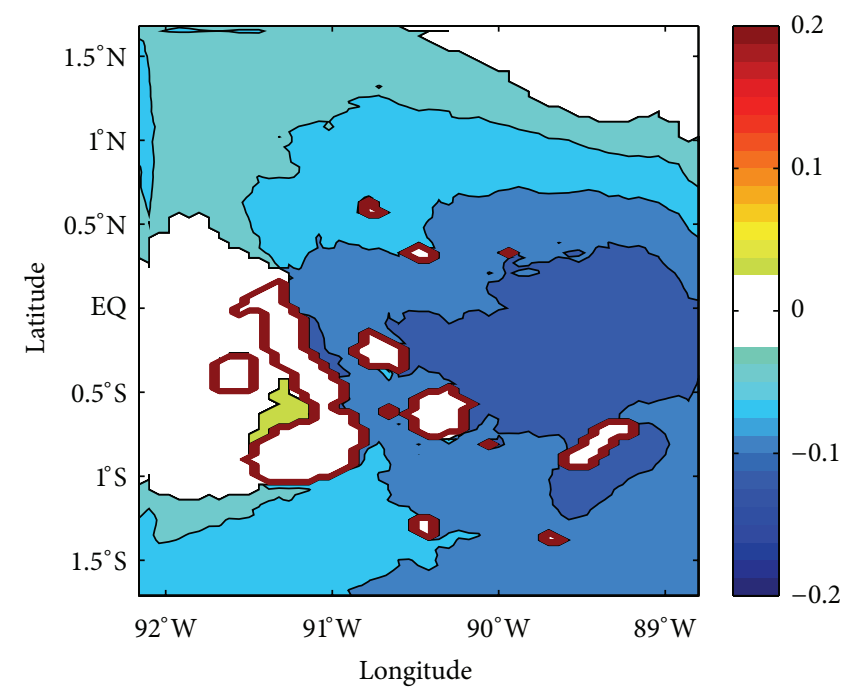

(c) SST and Peru $\left(89^{\circ} \mathrm{W}\right)$ correlation $($ sig $=0.05)$

Figure 22: The contour of correlation coefficients between the simulated (a) EUC, (b) Panama current, and (c) Peru current volume flux transport under the low resolution of $0.72^{\circ} \times 0.36^{\circ}$ and SST fields under the high resolution of $0.06^{\circ} \times 0.03^{\circ}$.

University (NCSU) using the High-Performance Computing (HPC) system at NCSU and the Bluefire supercomputer at NCAR/CISL.

\section{References}

[1] R. Bustamante, K. J. Collins, and R. Bensted-Smith, "Biodiversity conservation in the Galápagos Marine Reserve," Entomologie Supplement, vol. 68, pp. 45-52, 1999.

[2] K. Wyrtki, "Oceanography of the eastern equatorial Pacific Ocean," Oceanography and Marine Biology, vol. 4, pp. 33-68, 1966.

[3] J. A. Knauss, "Further measurements and observations of the cromwell current," Journal of Marine Research, vol. 24, pp. 205240, 1966.

[4] M. Stevenson M and V. Taft, "New evidence of the equatorial undercurrent east of the Galápagos Island," Journal of Marine Research, vol. 29, no. 2, pp. 103-115, 1971.
[5] A. Leetmaa, "Observations of near-equatorial flows in the eastern Pacific," Journal of Marine Research, vol. 40, pp. 357-370, 1982.

[6] D. M. Palacios, "Seasonal patterns of sea-surface temperature and ocean color around the Galápagos: regional and local influences," Deep-Sea Research II, vol. 51, no. 1-3, pp. 43-57, 2004.

[7] F. P. Chavez, P. G. Strutton, G. E. Friederich et al., "Biological and chemical response of the equatorial Pacific Ocean to the 1997-98 El Niño," Science, vol. 286, no. 5447, pp. 2126-2131, 1999.

[8] G. Feldman, "Patterns of phytoplankton production around the Galápagos Islands," in Tidal Mixing and Plankton Dynamics, M. J. Bowman, R. T. Barber, and C. N. K. Mooers, Eds., Lecture Notes on Coastal and Esutarine Studies, pp. 77-106, Springer, Berlin, Germany, 1986.

[9] M. A. Riedinger, M. Steinitz-Kannan, W. M. Last, and M. Brenner, "A similar 6100 C-14C yr record of El Niño activity 
from the Galápagos Islands," Journal of Paleolimnology, vol. 27, no. 1, pp. 1-7, 2002.

[10] D. T. Rodbell, G. O. Seltzer, D. M. Anderson, M. B. Abbott, D. B. Enfield, and J. H. Newman, "An asymptotically equal to 15,000year record of El Niño-Driven alluviation in Southwestern Ecuador," Science, vol. 283, no. 5401, pp. 516-520, 1999.

[11] G. P. Podestá and P. W. Glynn, "Sea surface temperature variability in Panama and Galápagos: extreme temperatures causing coral bleaching," Journal of Geophysical Research, vol. 102, pp. 15749-15759, 1997.

[12] G. M. Wellington, A. E. Strong, and G. Merlen, "Sea surface temperature variation in the Galápagos Archipelago: a comparison between AVHRR nighttime satellite data and in situ instrumentation (1982-1998)," Bulletin of Marine Science, vol. 69, no. 1, pp. 27-42, 2001.

[13] M. Collins, S.-I. An, W. Cai et al., "The impact of global warming on the tropical Pacific Ocean and El Niño," Nature Geoscience, vol. 3, no. 6, pp. 391-397, 2010.

[14] J. L. Conroy, A. Restrepo, J. T. Overpeck et al., "Unprecedented recent warming of surface temperatures in the eastern tropical Pacific Ocean," Nature Geoscience, vol. 2, no. 1, pp. 46-50, 2009.

[15] R. B. Dunbar, G. M. Wellington, M. W. Colgan, and P. W. Glynn, "Eastern Pacific sea surface temperature since 1600 A.D.: the $\delta 18 \mathrm{O}$ record of climate variability in Galapagos corals," Paleoceanography, vol. 9, no. 2, pp. 291-315, 1994.

[16] C. Deser, A. S. Phillips, and M. A. Alexander, "Twentieth century tropical sea surface temperature trends revisited," Geophysical Research Letters, vol. 37, no. 10, article L1070, 2010.

[17] N. A. Rayner, D. E. Parker, E. B. Horton et al., "Global analyses of sea surface temperature, sea ice, and night marine air temperature since the late nineteenth century," Journal of Geophysical Research D, vol. 108, no. D14, article 4407, 2003.

[18] A. Kaplan, M. A. Cane, Y. Kushnir, A. C. Clement, M. B. Blumenthal, and B. Rajagopalan, "Analyses of global sea surface temperature 1856-1991," Journal of Geophysical Research, vol. 103, no. C9, pp. 18567-18589, 1998.

[19] IPCC, IPCC Fourth Assessment Report: Climate Change 2007 (AR4), IPCC, Geneva, Switzerland, 2007.

[20] K. B. Karnauskas, G. C. Johnson, and R. Murtugudde, "An equatorial ocean bottleneck in global climate models," Journal of Climate, vol. 25, no. 1, pp. 343-349, 2012.

[21] R. Bleck, "An oceanic general circulation model framed in hybrid isopycnic-Cartesian coordinates," Ocean Modelling, vol. 4, no. 1, pp. 55-88, 2002.

[22] E. P. Chassignet, L. T. Smith, G. R. Halliwell, and R. Bleck, "North Atlantic Simulations with the Hybrid Coordinate Ocean Model (HYCOM): impact of the vertical coordinate choice, reference density, and thermobaricity," Journal of Physical Oceanography, vol. 33, pp. 2504-2526, 2003.

[23] G. R. Halliwell Jr., "Evaluation of vertical coordinate and vertical mixing algorithms in the HYbrid-Coordinate Ocean Model (HYCOM)," Ocean Modelling, vol. 7, no. 3-4, pp. 285-322, 2004.

[24] D. R. Cayan, "Latent and sensible heat flux anomalies over the northern oceans: driving the sea surface temperature," Journal of Physical Oceanography, vol. 22, no. 8, pp. 859-881, 1992.

[25] D. Cayan, "Latent and sensible heat flux anomalies over the northern ocean: the connection to monthly atmospheric circulation," Journal of Climate, vol. 5, pp. 354-369, 1992.

[26] S. Levitus and T. Boyer, World Ocean Atlas 1994, Volume 4: Temperature, NOAA Atlas NESDIS 4, US Department of Commerce, Washington, DC, USA, 1994.
[27] S. Levitus, R. Burgett, and T. Boyer, World Ocean Atlas 1994, Volume 3: Salinity, NOAA Atlas NESDIS 3, US Department of Commerce, Washington, DC, USA, 1994.

[28] W. G. Large, J. C. McWilliams, and S. C. Doney, "Oceanic vertical mixing: a review and a model with a nonlocal boundary layer parameterization," Reviews of Geophysics, vol. 32, no. 4, pp. 363-403, 1994.

[29] W. V. Sweet, J. M. Morrison, Y. Liu et al., "Tropical instability wave interactions within the Galápagos Archipelago," Deep-Sea Research Part I: Oceanographic Research Papers, vol. 56, no. 8, pp. 1217-1229, 2009.

[30] R. Kistler, E. Kalnay, W. Collins et al., "The NCEP-NCAR 50year reanalysis: monthly means CD-ROM and documentation," Bulletin of the American Meteorological Society, vol. 82, no. 2, pp. 247-267, 2001.

[31] K. E. Trenberth, “The Definition of El Niño," Bulletin of the American Meteorological Society, vol. 78, no. 12, pp. 2771-2777, 1997.

[32] R. W. Reynolds and T. M. Smith, "Improved global sea surface temperature analyses using optimum interpolation," Journal of Climate, vol. 7, no. 6, pp. 929-948, 1994.

[33] Y. Liu, Simulation of ocean circulation around the Galápagos archipelago using a Hybrid Coordinate Ocean Model (HYCOM) [Ph.D. dissertation], North Carolina State University, Raleigh, NC, USA, 2010.

[34] G. A. Vecchi, B. J. Soden, A. T. Wittenberg, I. M. Held, A. Leetmaa, and M. J. Harrison, "Weakening of tropical Pacific atmospheric circulation due to anthropogenic forcing," Nature, vol. 441, no. 1, pp. 73-76, 2006.

[35] G. A. Vecchi and B. J. Soden, "Global warming and the weakening of the tropical circulation," Journal of Climate, vol. 20, no. 17, pp. 4316-4340, 2007.

[36] G. C. Johnson, B. M. Sloyan, W. S. Kessler, and K. E. McTaggart, "Direct measurements of upper ocean currents and water properties across the tropical Pacific during the 1990s," Progress in Oceanography, vol. 52, no. 1, pp. 31-61, 2002.

[37] S.-P. Xie and S. G. H. Philander, "A coupled ocean-atmosphere model of relevance to the ITCZ in the eastern Pacific," Tellus A, vol. 46, no. 4, pp. 340-350, 1994.

[38] P. C. Fiedler and L. D. Talley, "Hydrography of the eastern tropical Pacific: a review," Progress in Oceanography, vol. 69, no. 2-4, pp. 143-180, 2006.

[39] M. J. McPhaden, A. J. Busalacchi, R. Cheney et al., "The tropical ocean-global atmosphere observing system: a decade of progress," Journal of Geophysical Research, vol. 103, no. 7, pp. 14169-14240, 1998.

[40] G. J. Edgar, S. Banks, J. M. Fariña, M. Calvopiña, and C. Martínez, "Regional biogeography of shallow reef fish and macro-invertebrate communities in the Galapagos archipelago," Journal of Biogeography, vol. 31, no. 7, pp. 1107-1124, 2004.

[41] E. Wolanski and S. Spagnol, "Environmental degradation by mud in tropical estuaries," Regional Environmental Change, vol. 1, no. 3-4, pp. 152-162, 2000. 

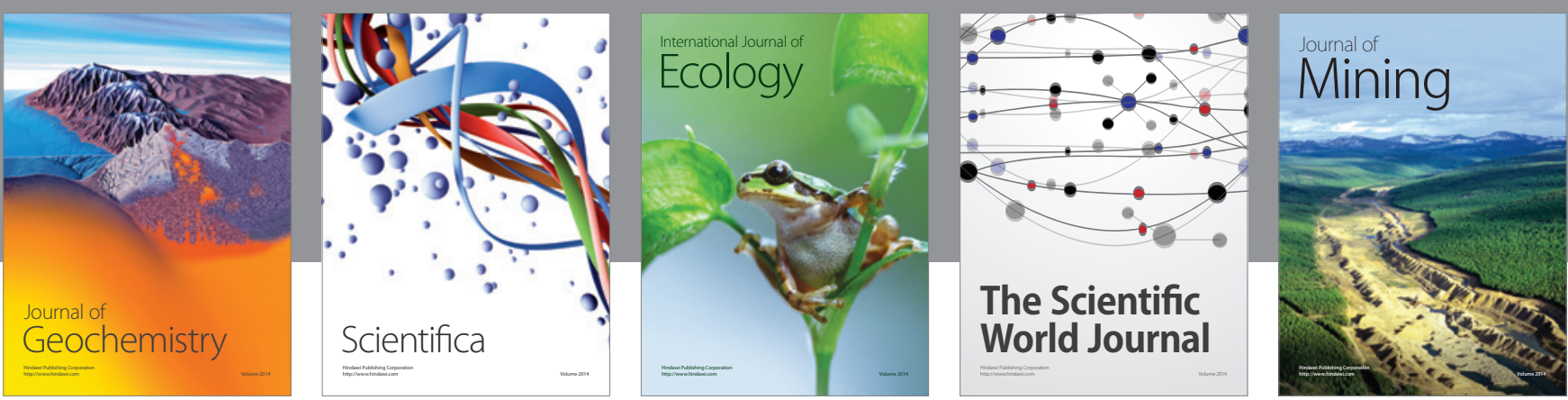

The Scientific World Journal
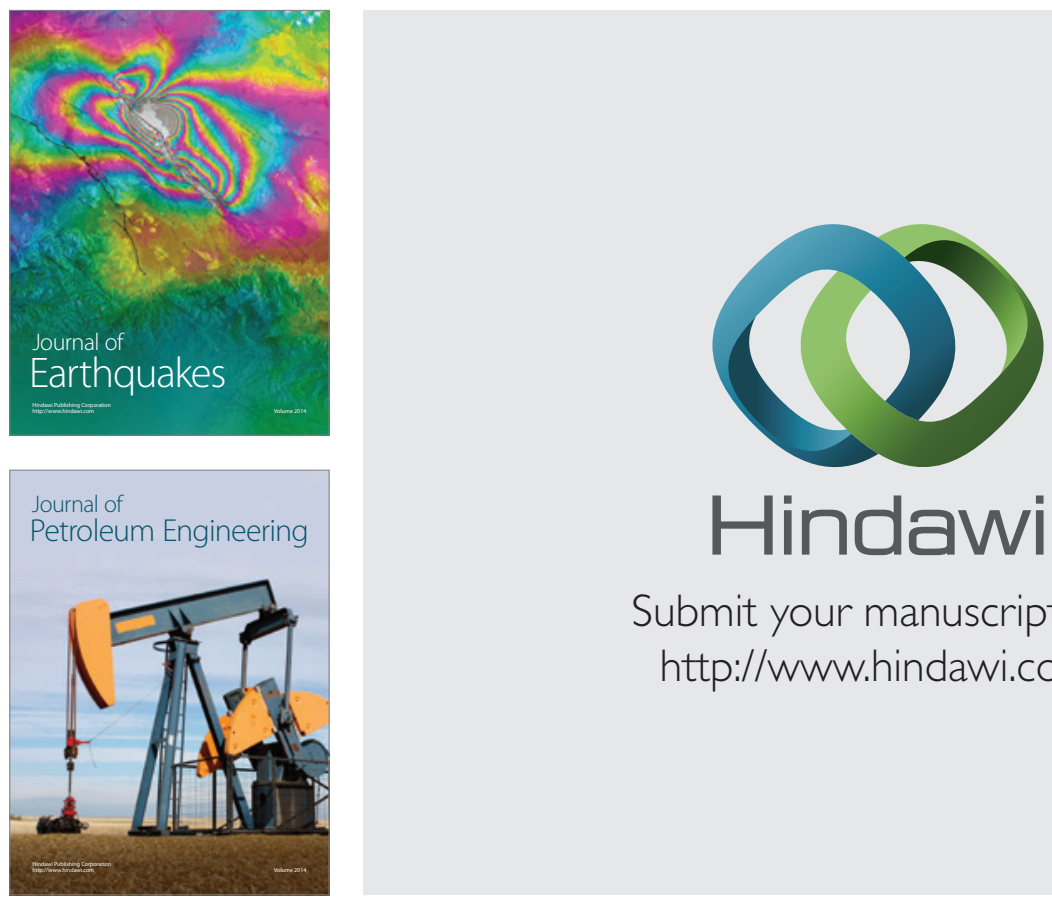

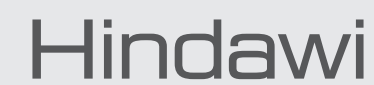

Submit your manuscripts at

http://www.hindawi.com
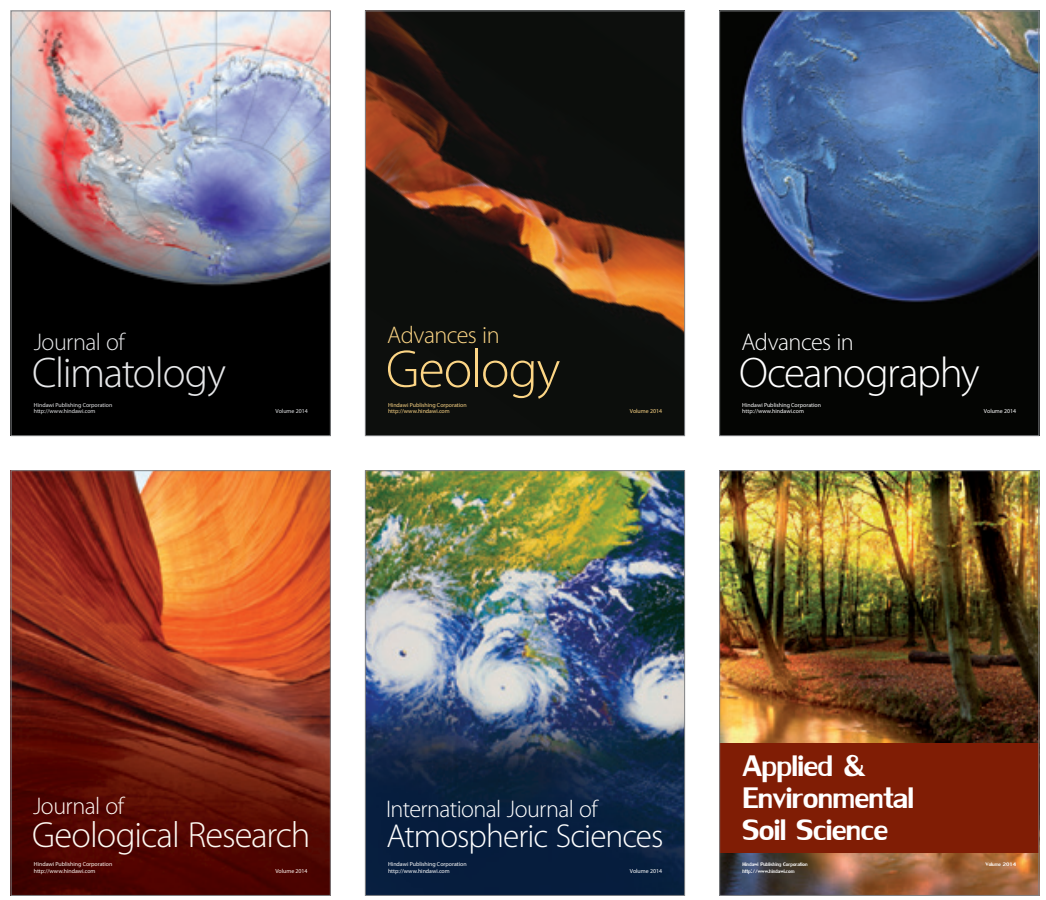
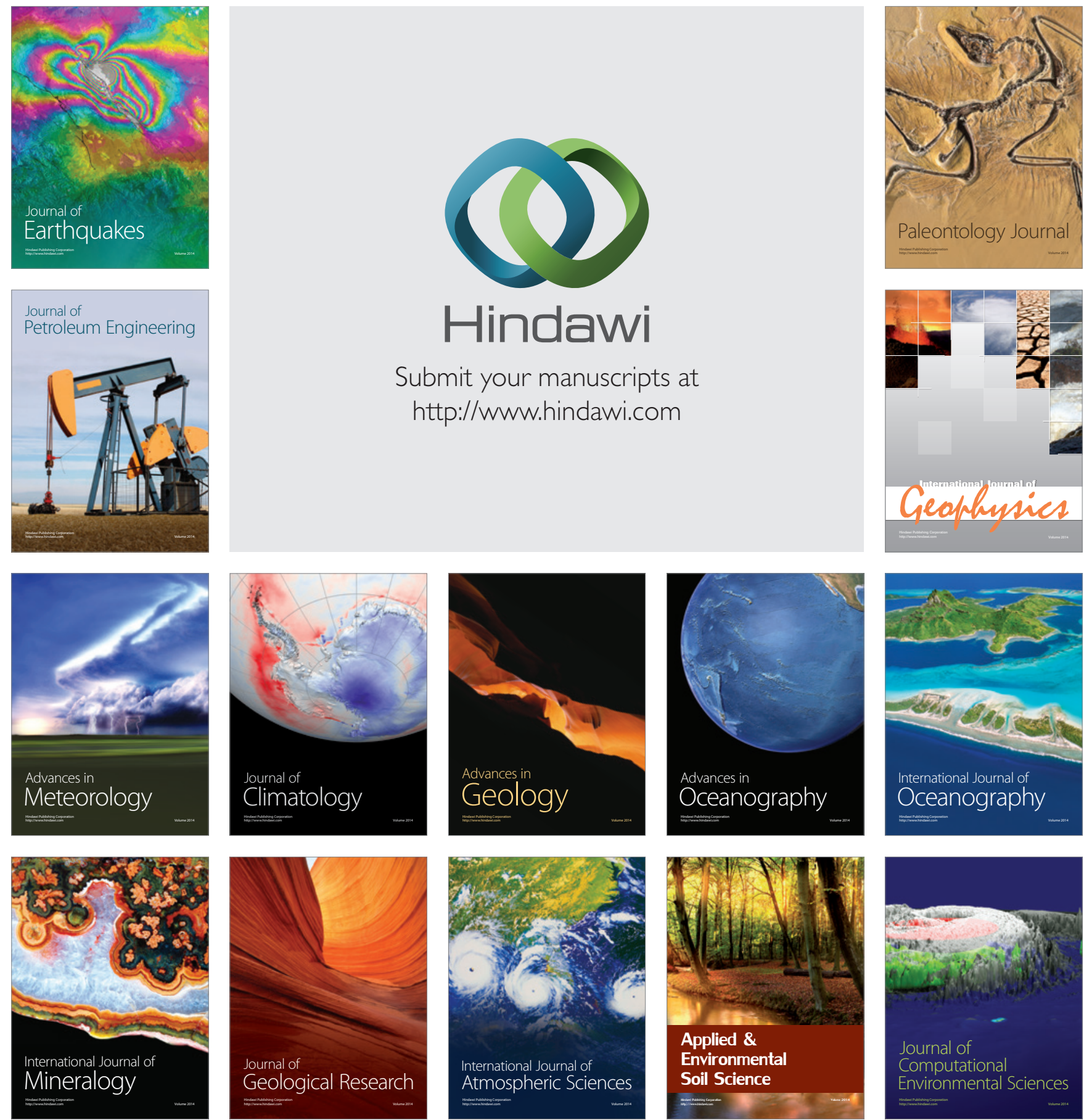